السلوك الاجتماعى الإيجابى للى طالبات الكليات العلمية

\title{
والإنسانية
}

بجامعتالكويت (دراستّمقارنت)

\author{
إعــــاد \\ الباحثة/ هلدى ملوح عسكر الفضلي \\ مدرس مساعد علم النفس \\ قسم علم النفس - كليت العلوم الاجتماعيت - جامعت الكويت
}




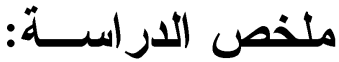

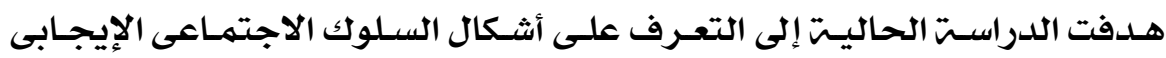

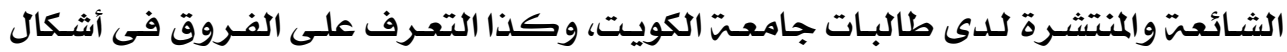

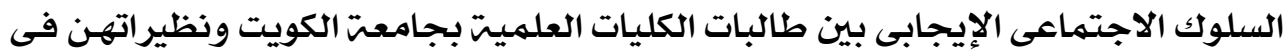

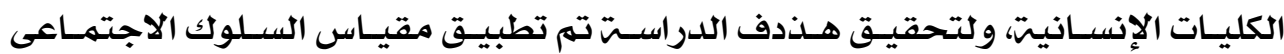

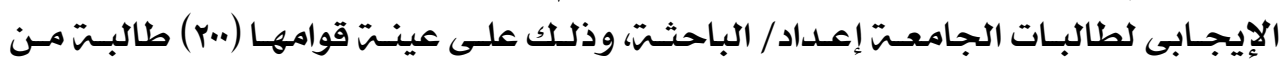

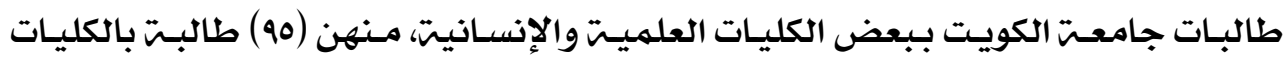

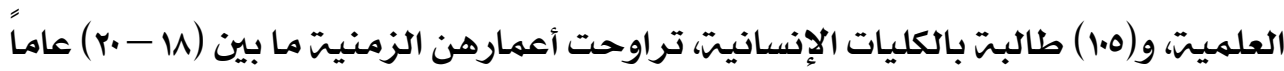

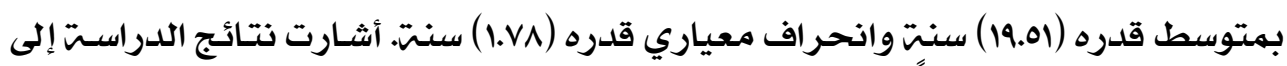

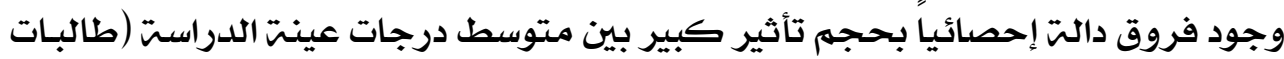

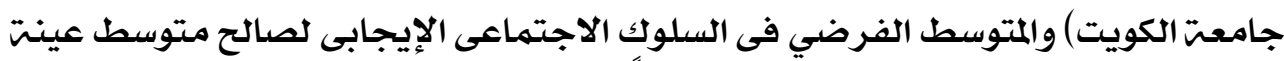

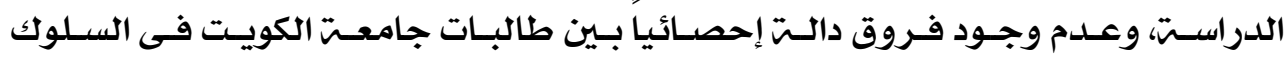
الاجتماعى الإيجابى تبعاً للتخصص الدور الدراسى "نوع الكليت" (علميت - إنسانيتة).

الكلمـــات المفتاحيــةة: السـلوك الاجتهـاعى الإيجـابى - الكليـات العلميـت - الكليـات الإنسانيت. 
لما كانت الإيجابيت هى صميم الكائن البشرى، فبم يعُد من المقبول تصور الإنسان

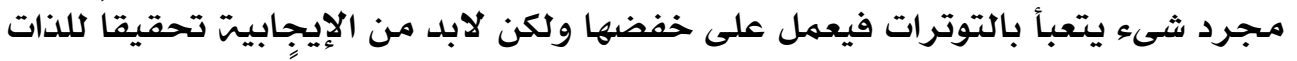

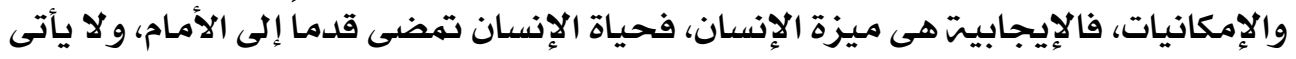

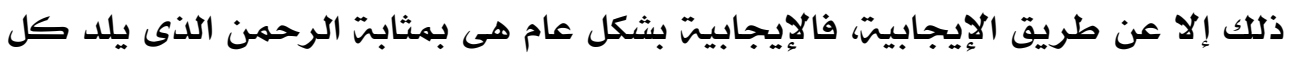

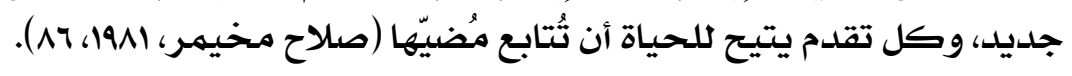

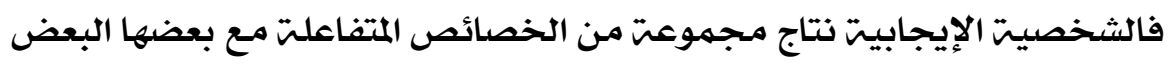

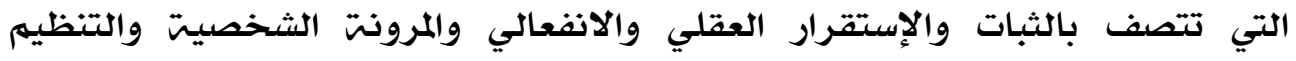

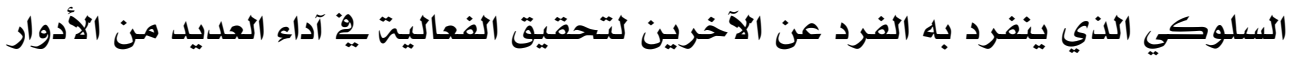

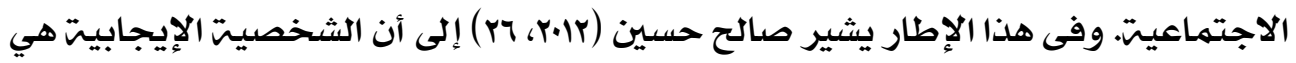

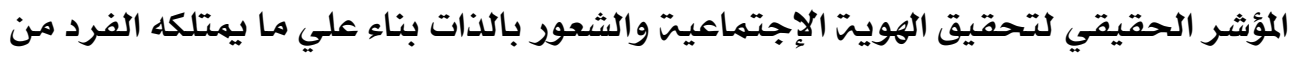

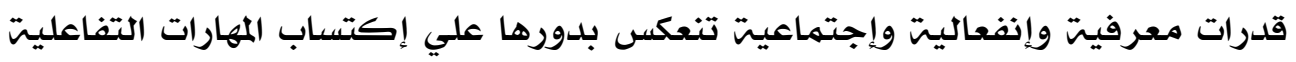

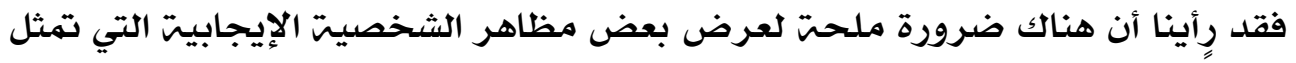
مطلبا للنجاح والترقي وتحقيق التوافق الإجتماعي.

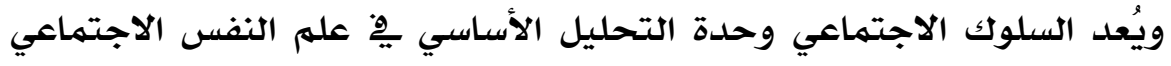

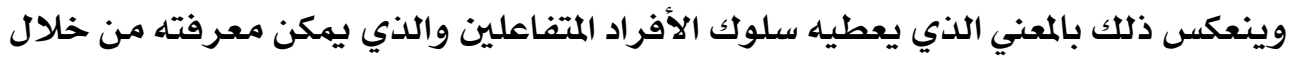

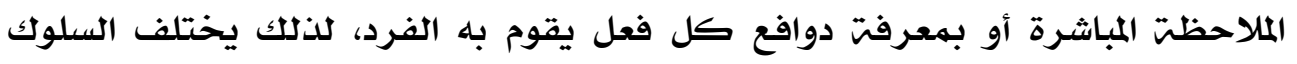

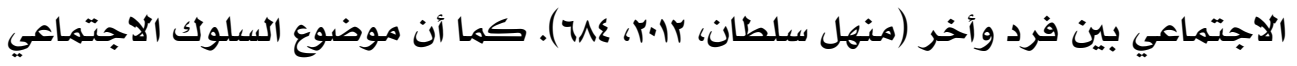

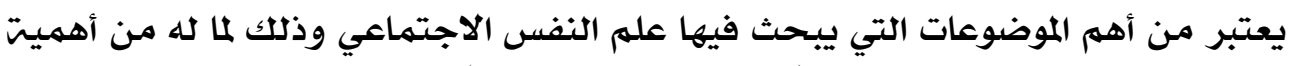

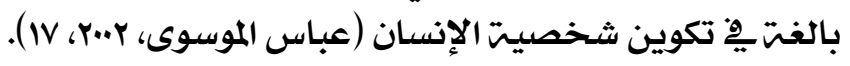

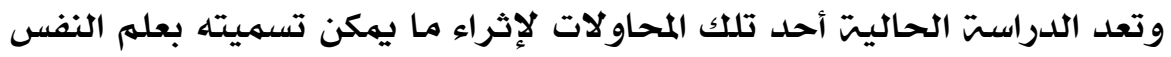

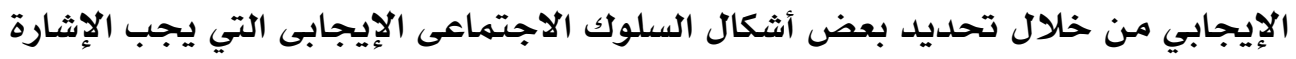

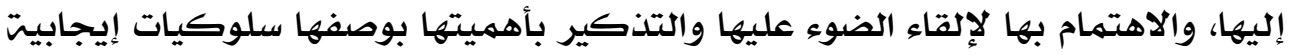

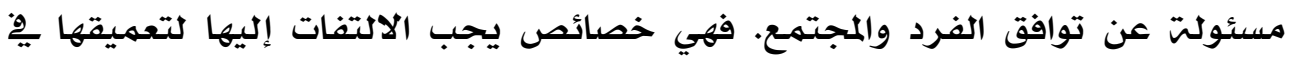

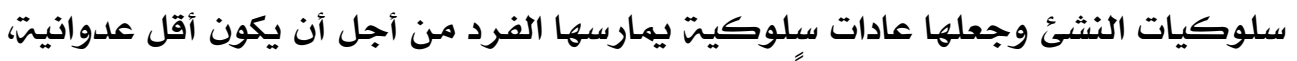
وأكثر مشاركتة وقبو لاجا اجتماعياً.

مشكلة الار اســة:

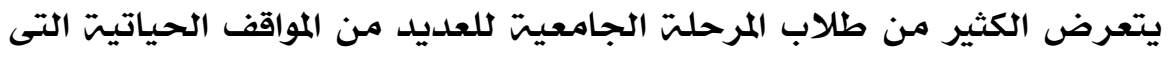

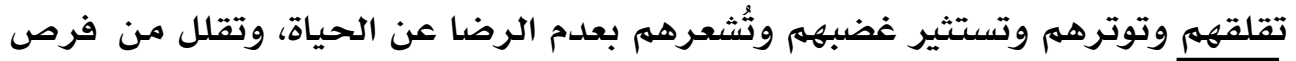
الباحثة/ هدى ملوح عسكر الضضلي 
ممارستهم للسلوكك الاجتماعى الإيجابى. وفى هذا الصدد تشير ساجدة السعدى (.ا.r، 79)

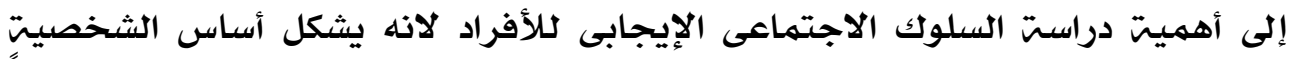

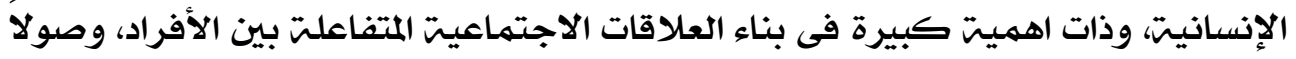

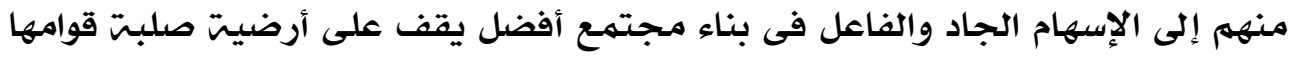
فهم السلوك والجماعتة.

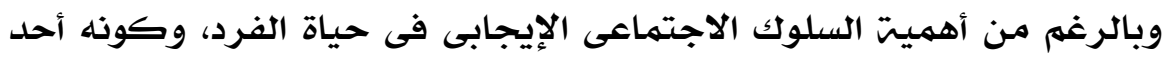

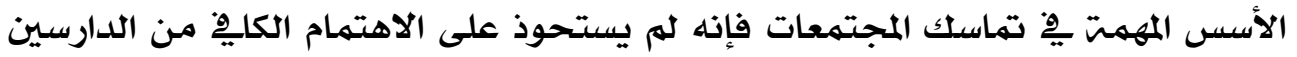

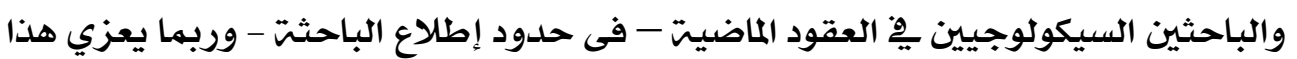

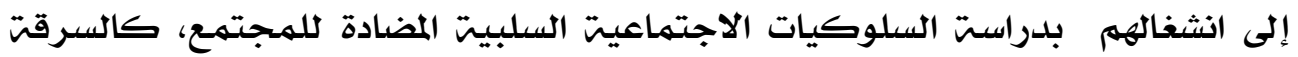

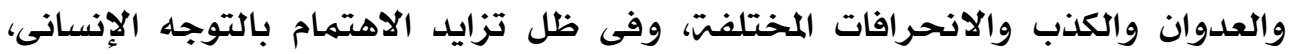

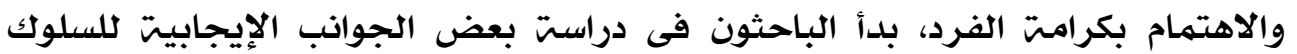

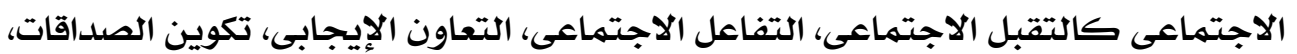

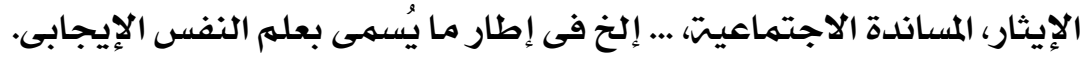

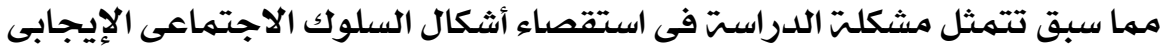

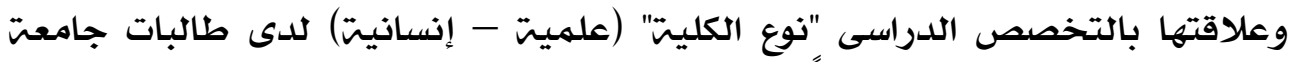

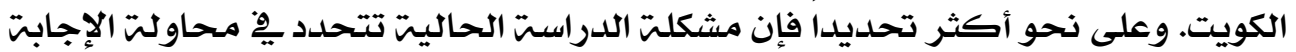

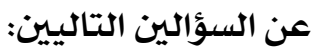

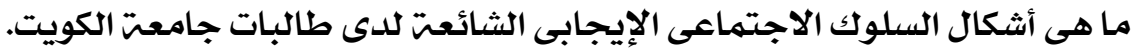

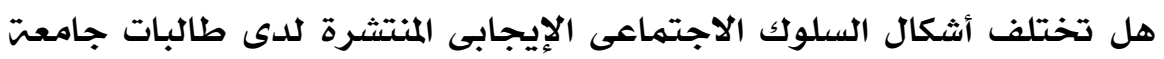

$$
\text { الكويت باختلاف التخصص الدراسى "نوع الكليت" (علميت - إنسانيت). }
$$

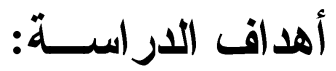

تهدف الدراستة الحاليت إلى التعرف على أشكال السلولك الاجتماعى الإيجابى

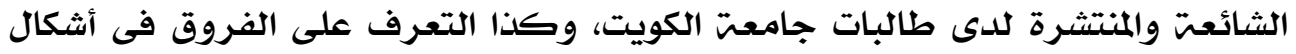

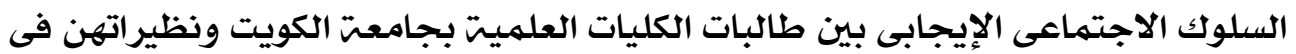
الكليات الإنسانيت.

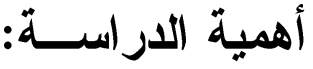

تتحدد أهميت الدراست الحاليت فى كونها ثُعد إضافت جديدة إلى التراث

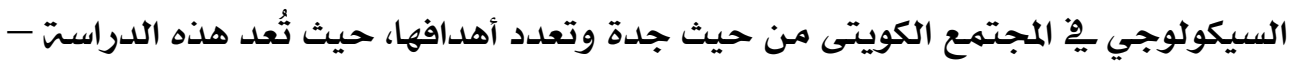


مِّ حدود إطلاع الباحثت - هي الدراست الأولى هِْ الكويت التي تتناول أشكال السلوك

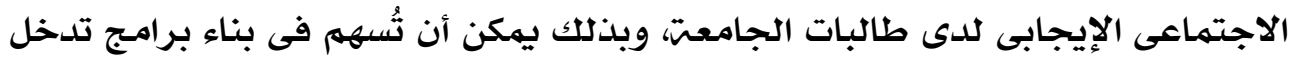

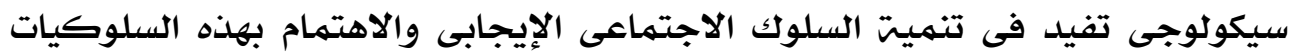

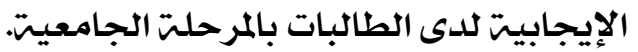

\section{مصطاحست اللدراسـة:}

\section{1- السلوك الاجتماعى الإيجابى Positive Social Behavior:}

هو أي تصرف أو فعل أو نهط سلوكي بناء اجتماعيا أو مفيد على نحو ما

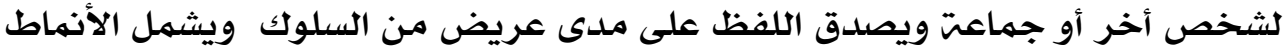

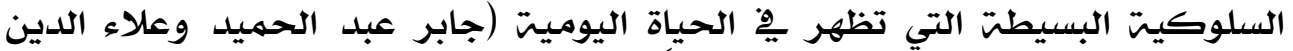

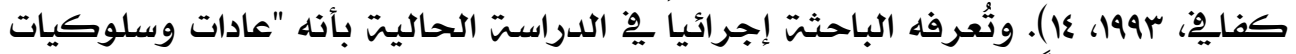
مقبولت اجتماعيا تساعد المتعلم فى التفاعل الاجتماعي الذي يعد بهثابت مشاركت بته بين

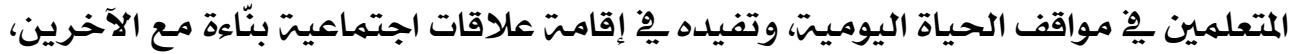
ويتخذ السلوك الاجتماعى الإيجابى فى الدراست الحاليت الأثكال التاليتي: التقبل

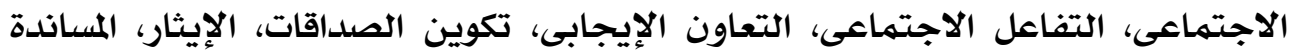

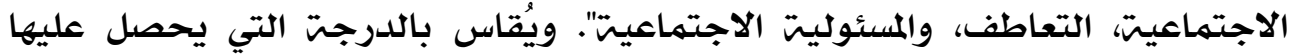

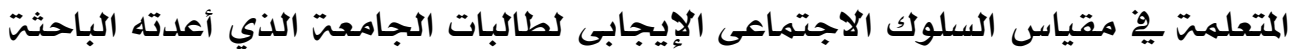
الحاليت.

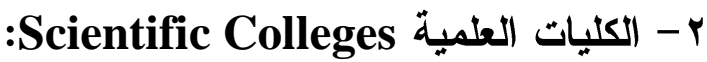
يقصد بهم فى الدراستّ الحاليت "الكليات العلهيت بجامعت الكويت وتثهل كليات: العلوم، الطب، والصيدلث".

Faculties of Humanities الكليات الإسناتية يقصد بهم فى الدراست الحاليت "الكليات الإنسانيت بجامعت الكويت وتشهل كليات: "العلوم الاجتماعيتة، الآداب، والتربيت.

\section{الإطار النظرى والدر اسات السابقة:} لم يشهد التراث السيكولوجي مصطلحاً فضفاضاً كهصطلح السلوك الاجتماعي الإيجابي، والمتتبع للدراسـات والبحوث السيكولوجيت يلحظ علدم اتفاق علماء النفس على تعريف واضتح ومحدد لهذا المصطلح، مها يعكس الرغبت والحاجت الماستش إلي إيجاد تعريف 


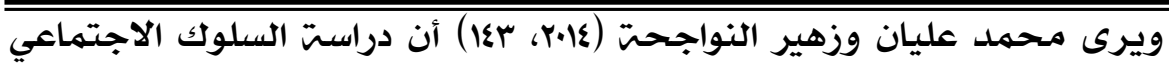

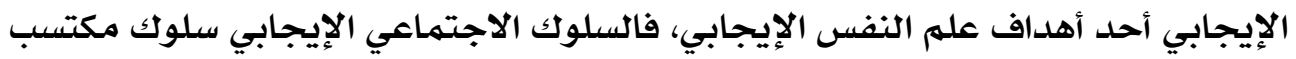

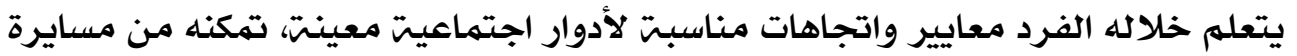

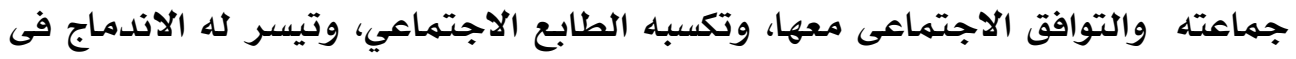

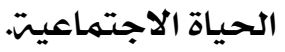

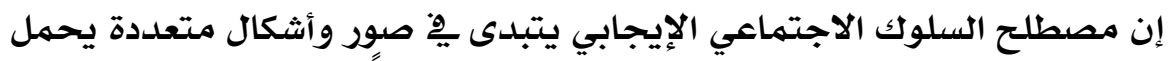

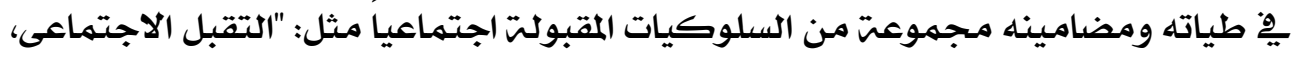

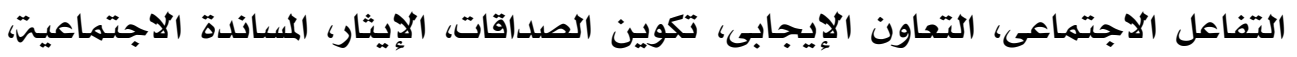

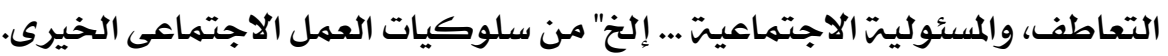

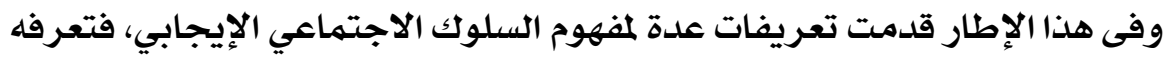
كلاري (Clary, 1994, 96) بأنه "السلوك المفيد للآخرين، وهو عكس السلوك المضاد

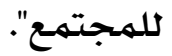
ويذكر (Kennedy, 2011) أنه "عبارة عن نهط من السلوك يهدف لتقديم

$$
\text { النفع أو المنفعت لشخص ما أو لآخرين". }
$$

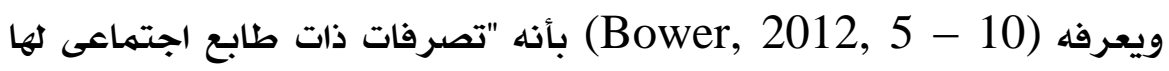

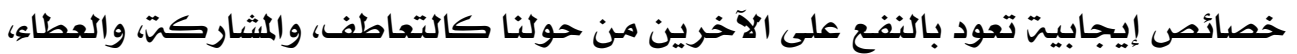

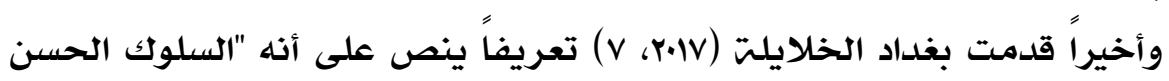
والتطوع".

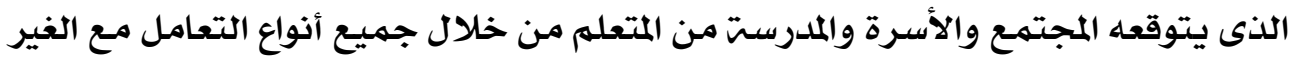

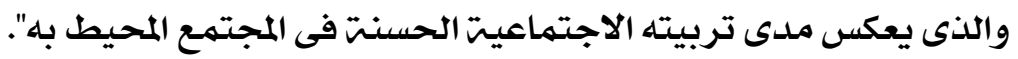
أثكال السلوك الاجتماعي الإيجابي: يتخذ السلوك الاجتماعى الإيجابى فى الدراست الحاليت الأثكال التاليت:

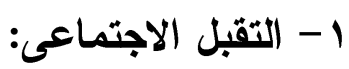

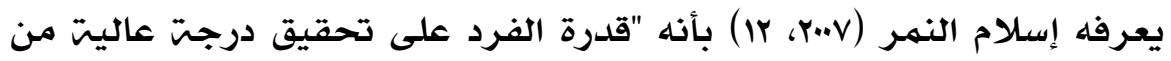

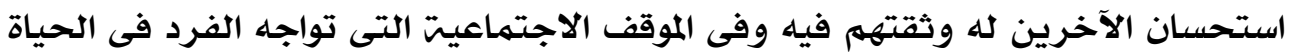

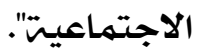

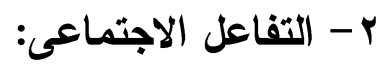

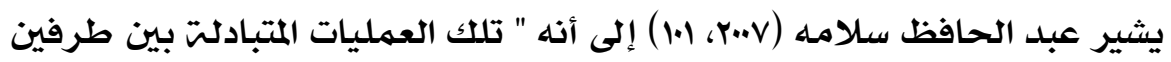

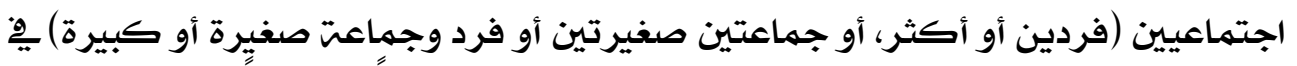

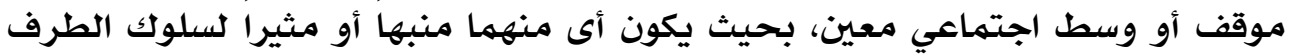

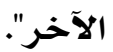




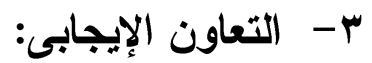

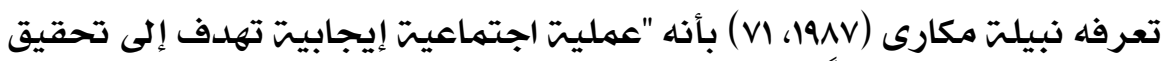

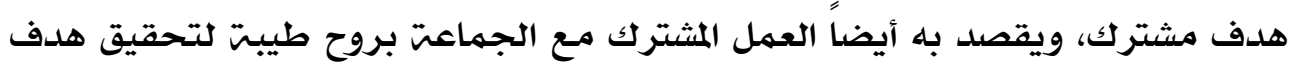

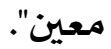
ع - تكوين الصداقات:

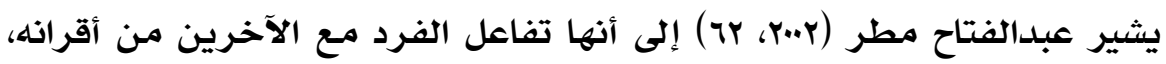

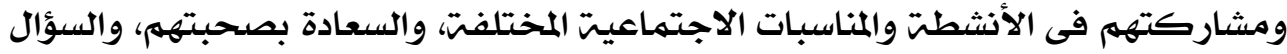
عنهم.

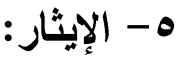

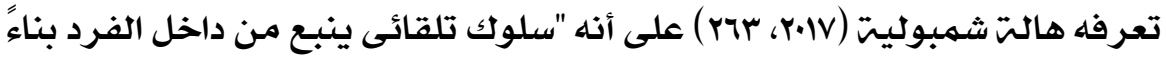

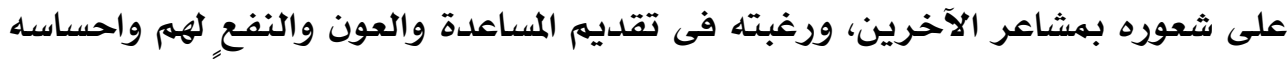

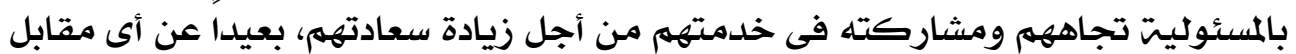

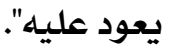

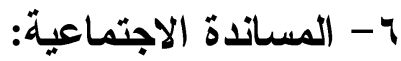

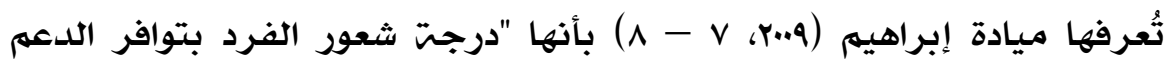

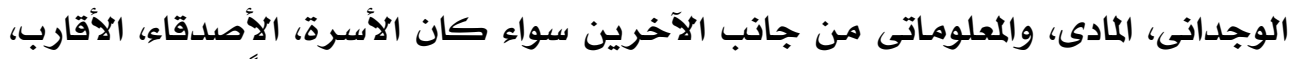

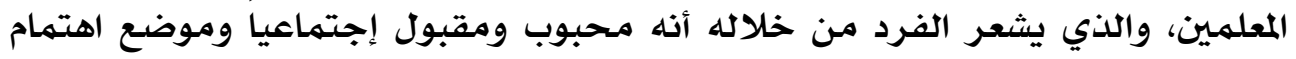

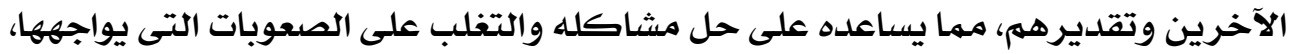
وخفض آثار تلك الصعوبات". V - V التعاطف:

يُعد التعاطف مهارة أساسيت وضروريت للحياة اليوميت. وِِّ ضوء ذلك يمكن

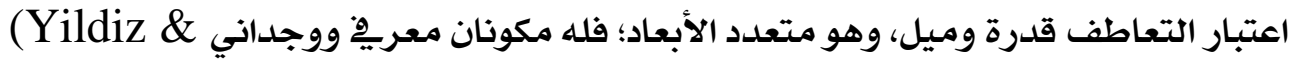

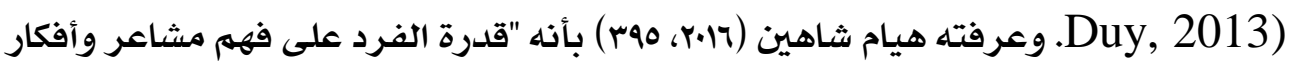

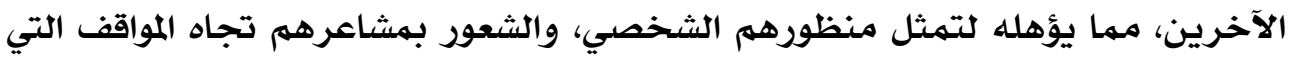
يعايشونها".

\section{- 1المسئولية الاجتماعية:}

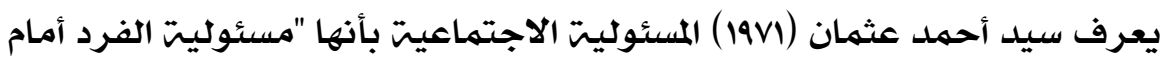

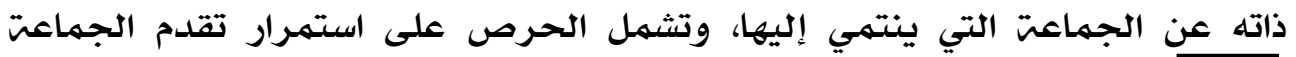

الباحثة/ هدى ملوح عسكر الفضلي 
وتماسكها وبلوغ أهدافها، وفهمه للهغزى الاجتماعي لأفعاله وما يترتب عليها من نتائج،

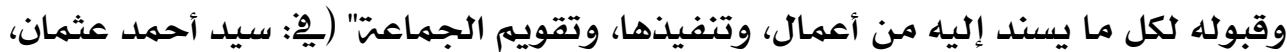
. (r.V - r. $\varepsilon$, r.).

ولقد أجريت العديد من الدراسـات والبحوث التي تناولت السلولك الاجتماعى

الإيجابى فى علاقته بالعديد من المتغيرات النفسيت والاجتمهاعيت منها:

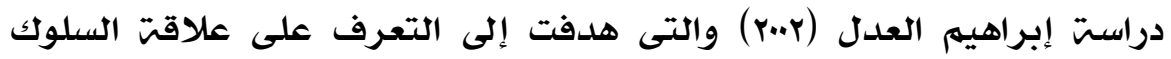

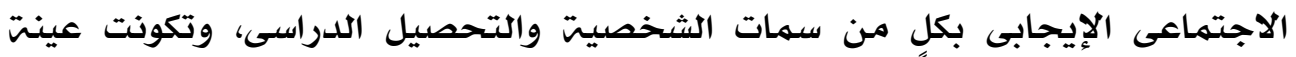

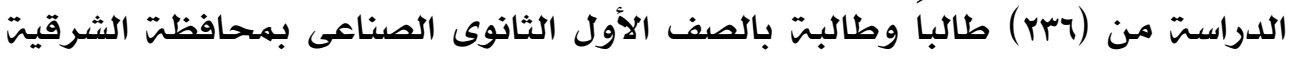
بجمهتريت مصر العربيت، وبتطبيق مقياسى لبهساعدة، والتعاون باعتبارهما من أبعاد

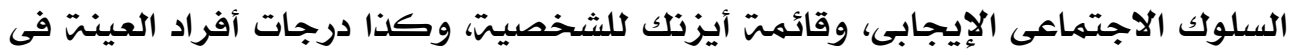

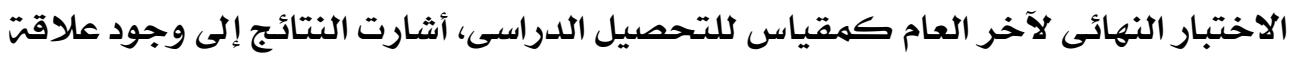
ارتباطيت دالت بين السلولك الاجتماعى الإيجابى وكل من سهات الشخصيتيت والتحصيل الدراسى.

ودراست كارلو وآخرين (Carlo et al., 1996) والتى هدفت إلى تناول بعض

المتغيرات المرتبطت بالأسباب الأخلاقيت للسلوك الاجتهاعي الإيجابي، وذلكك من خلابل الإل

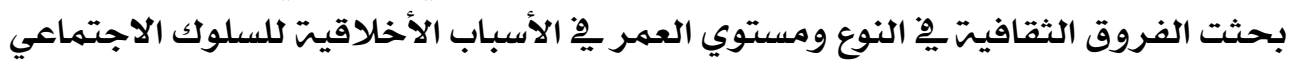

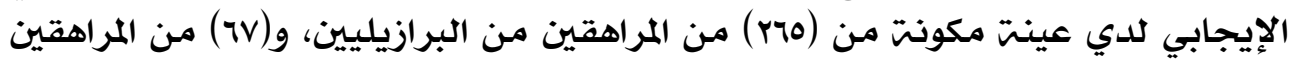

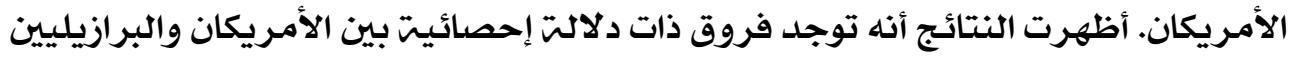

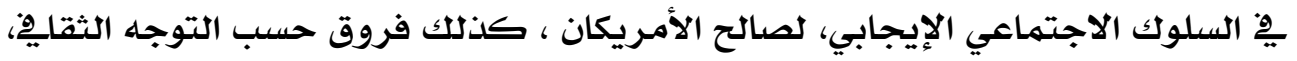
ومستوي العمر والنوع.

ودراست زهانج وتسيي (Zhang \& Tsui, 2009) التى هدفت إلى الكثف عن بالتباين الوظيفي بين الجماعات، والعلاقات داخل الجماعت لدي عينت من الأمـريكان

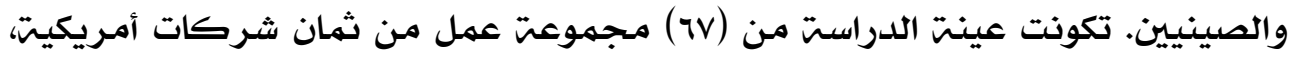
و(1\&9) مجمهوعت عمل من اثنتاعشر شركت صينيتة، وانتهت التحليلات الإحصائيت

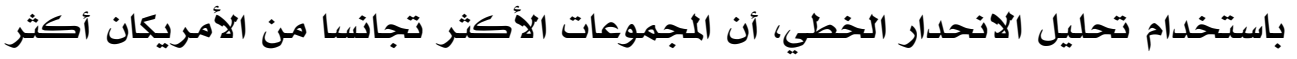

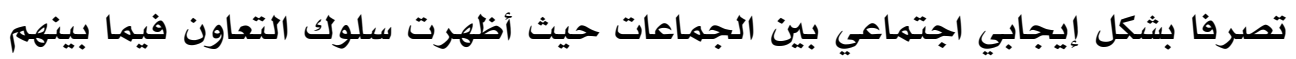

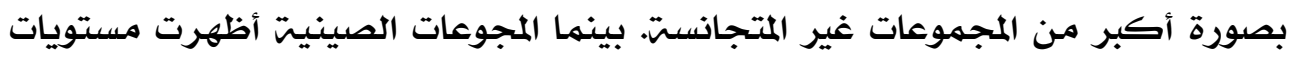

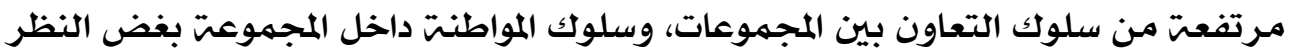

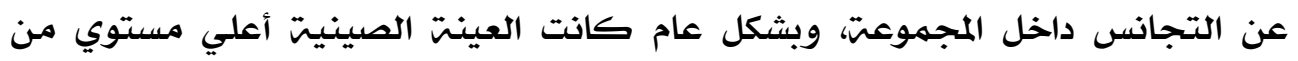
السلوك الاجتهاعي الإيجابي بين المجموعات، وأكثر مواطنت داخل المجموعت مقارنت بالأمريكان.

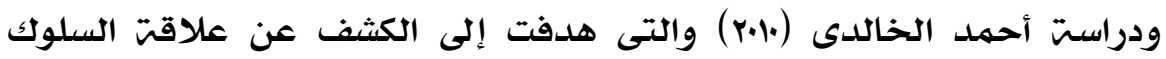

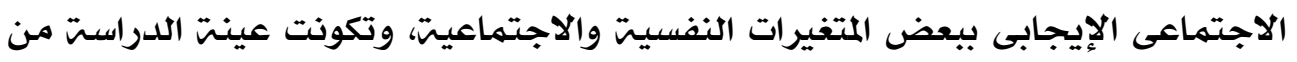

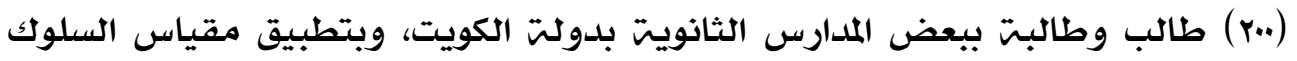
roo 
السلوك الاجتماعى الإيجابى لدى طالبات الكليات العلية والإنسانية

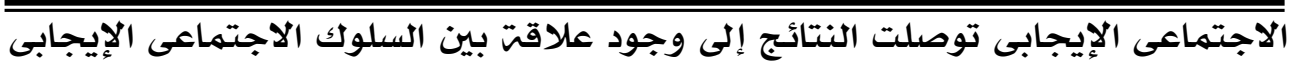

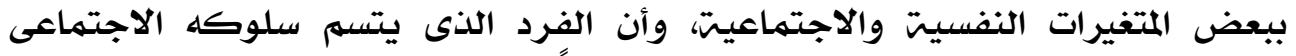

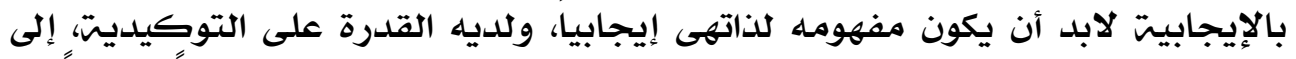

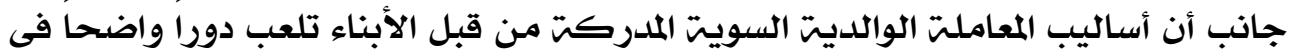
استدخال السلوك الاجتماعى الإيجابى.

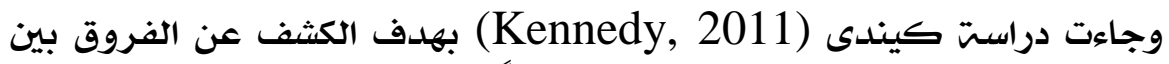

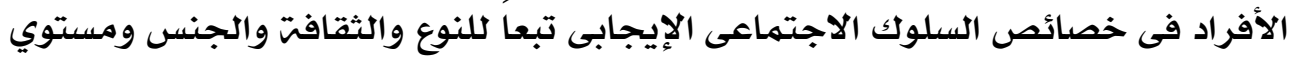

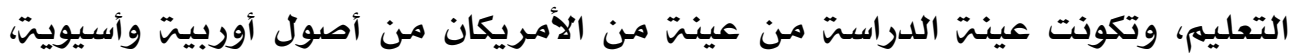

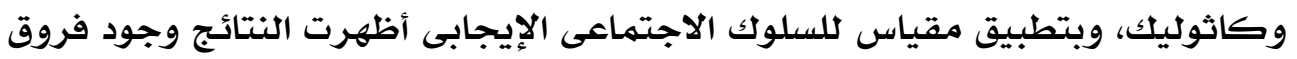

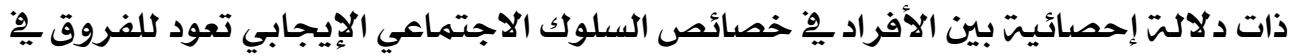

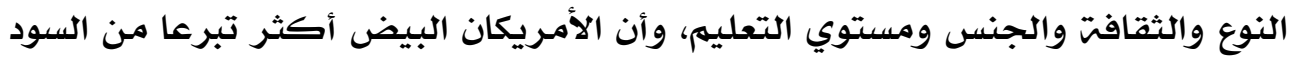

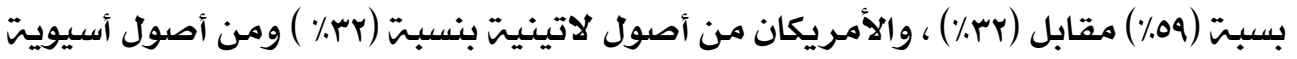

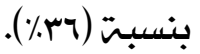
ودراست كمرى وآخرين (Kumru et al., 2012) والتى هدفت إلى التعرف

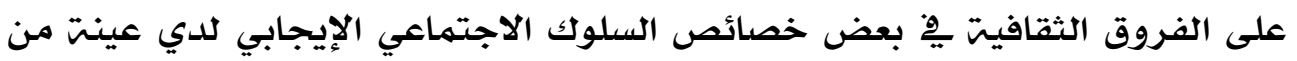

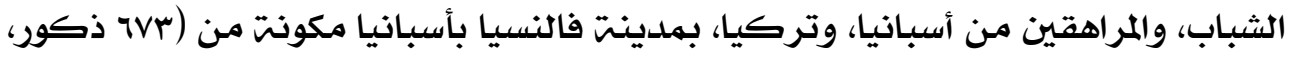

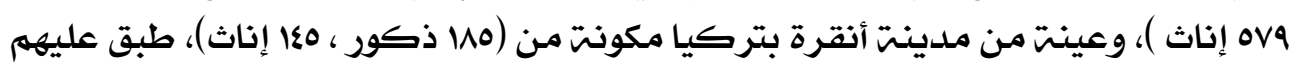

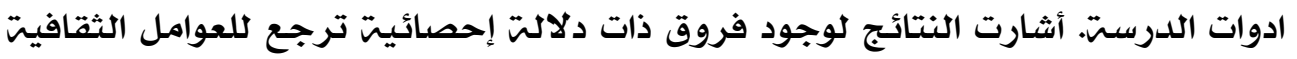

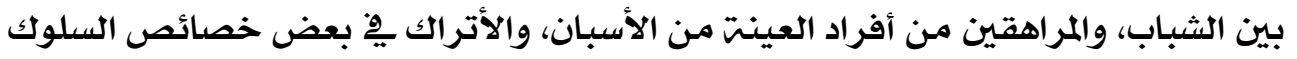

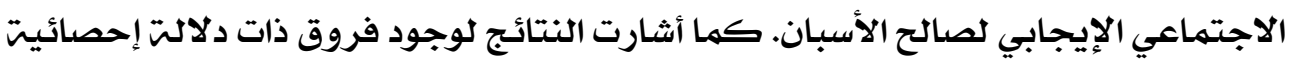

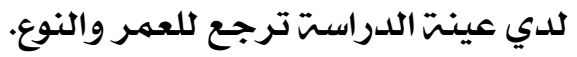

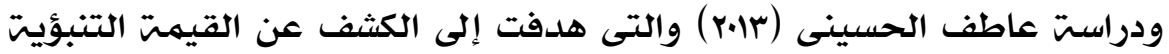

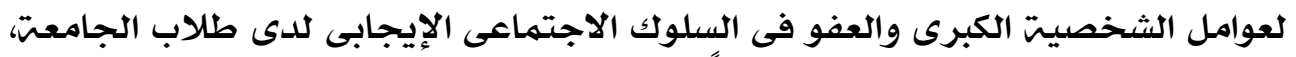

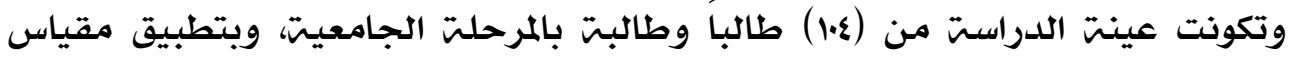

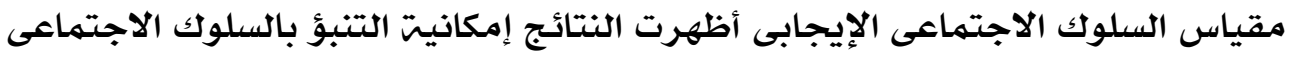

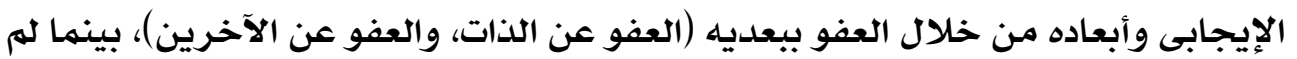

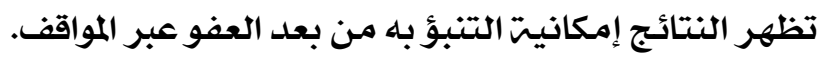

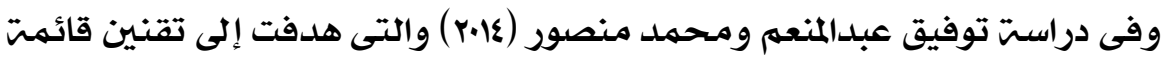

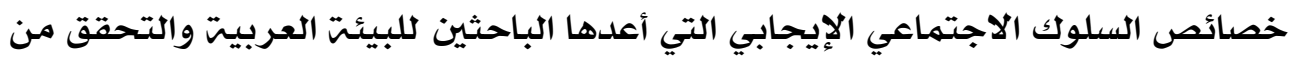

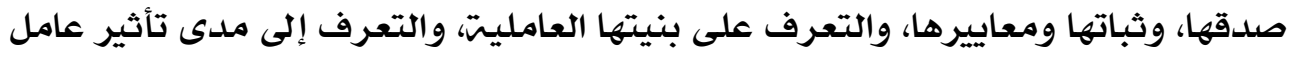

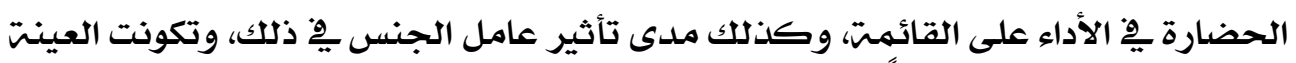

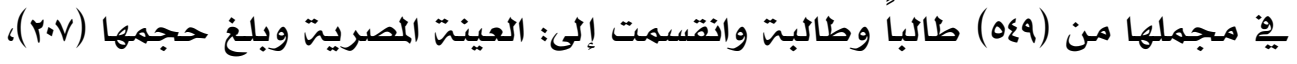

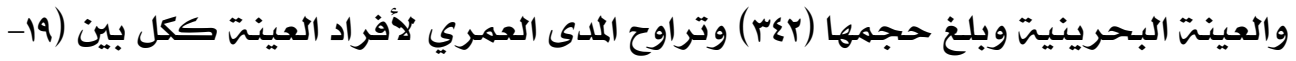

الباحثة/ هدى ملوح عسكر الفضلي 
أشارت ناما، وبتطبيق قائمت خصائص السلوك الاجتماعي الإيجابي والمكونت من (10.) مفردة.

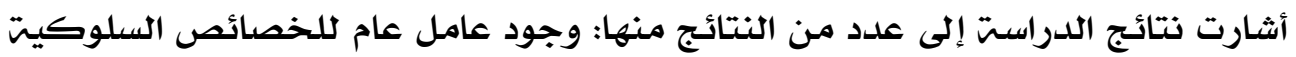

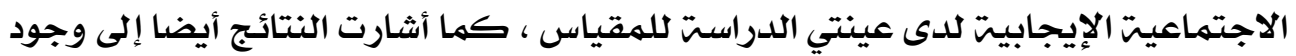

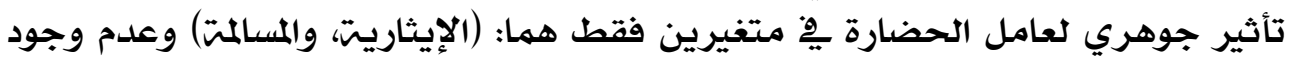

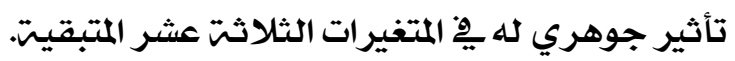

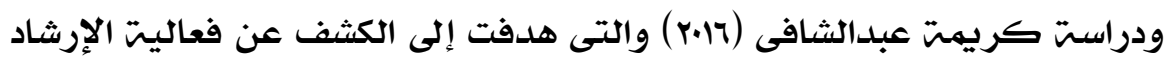

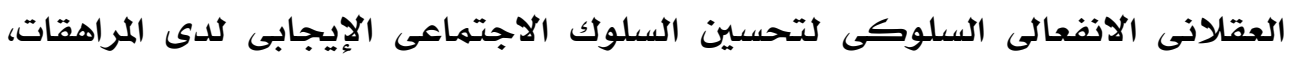

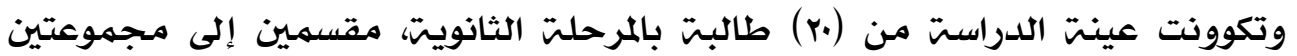

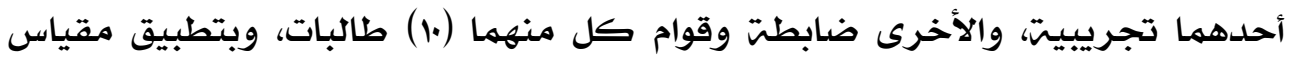

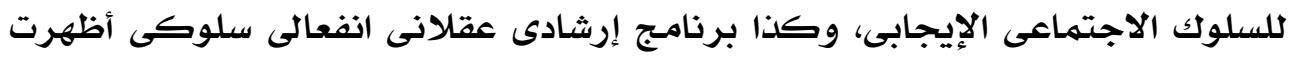

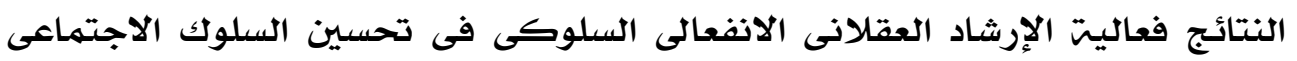
الإيجابى لدى أفراد المجموعت الإداد التجقالتى الانيبت.

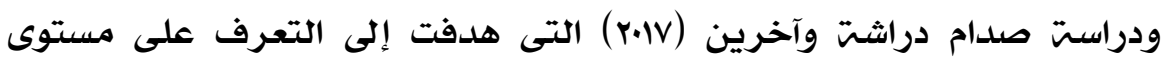

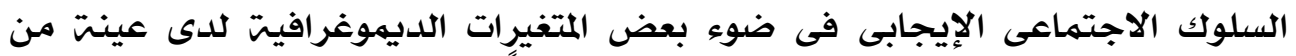

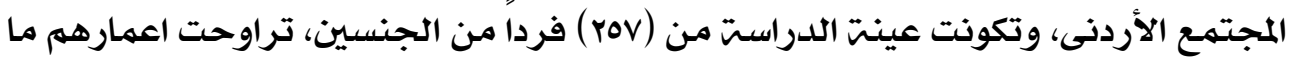

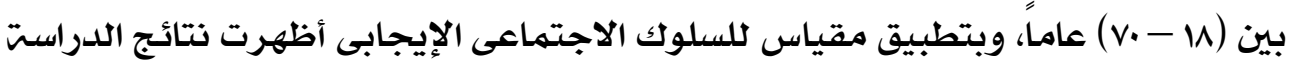

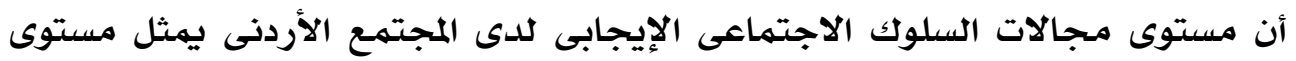

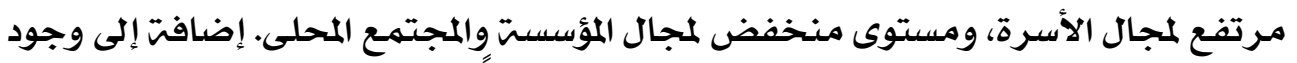

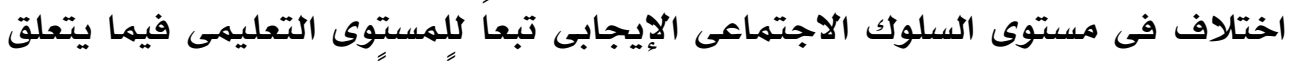

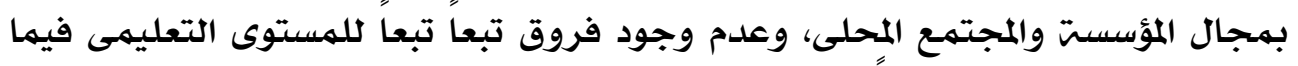

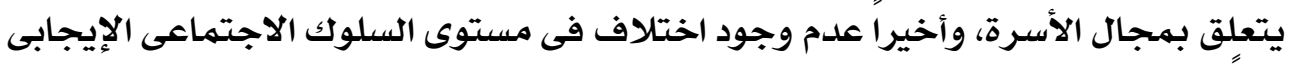

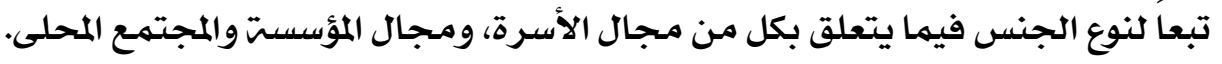

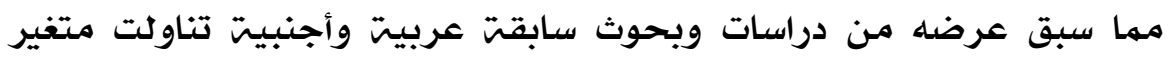

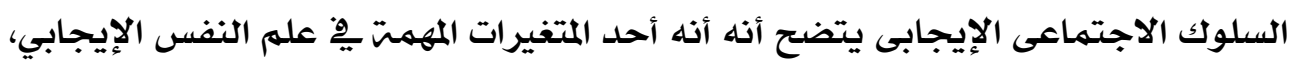

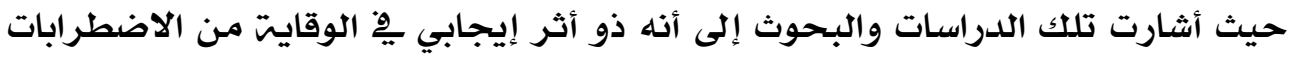
النفسيت والمثكلات السلوكيتة.

\section{فروض الار اســة:}

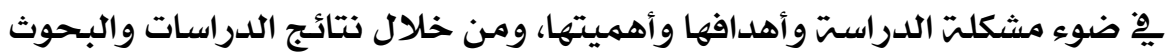

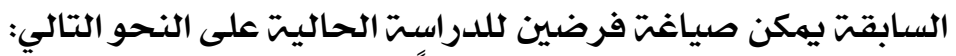

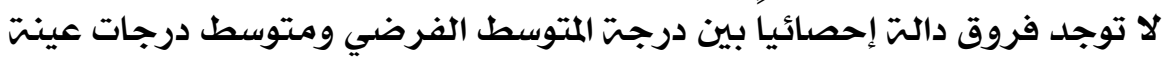

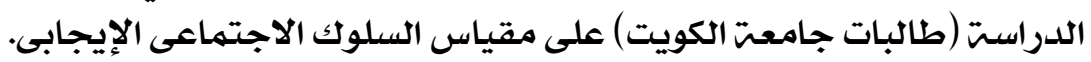


السلوك الاجتماعى الإيجابى لدى طالبات الكليات العلية والإنسانية

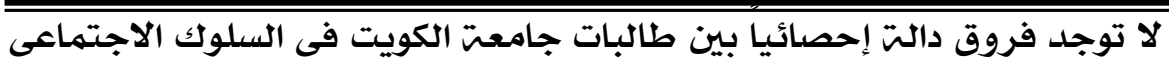

$$
\text { أجر الإيجابى تبعاً للتخصص الدراسى "نوع الكليتة" (علميت - إنسانية). }
$$

تستخدم الدراست الحاليت المنهج الوصفي للدراسات المسحيت والفارقت نظراً

كلائمته.

ب- مجتمع الار اســـة:

يتمثل مجتمع الدراستة من جميع طالبات جامعت الكويت ببعض الكليات العلميت

والإنسانيت.

ج- عينة الار اســـة:

1- عينة الاراسة الاستطلاعية: تكونت من (•A) طالبت من طالبات جامعت

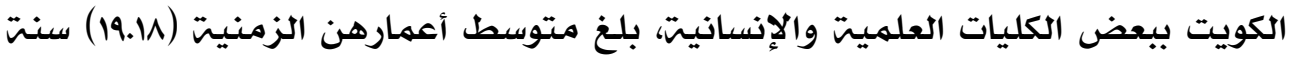

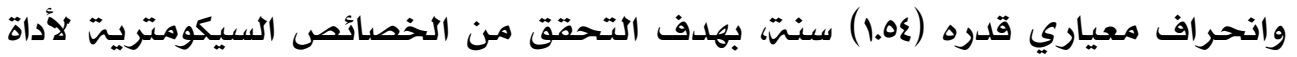
الدراست.

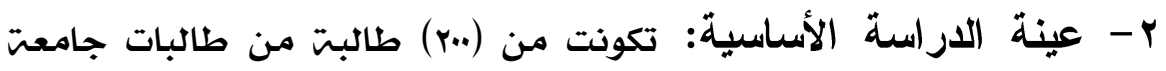

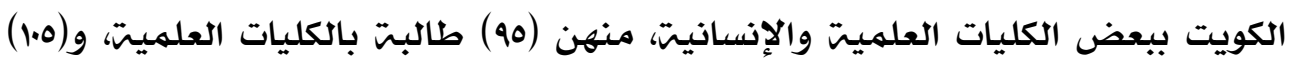

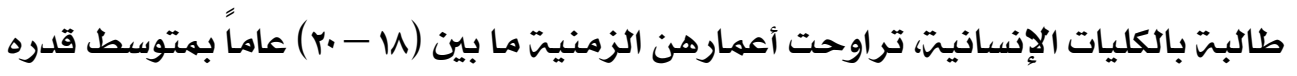
(19.01) سنت وانحراف معياري قدره (1.V^) سنتي.

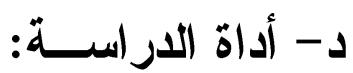

مقياس السلوك الاجتماعى الإيجابى لطالبات الجامعة: إعداد/ الباحثة

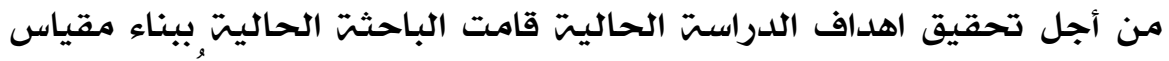

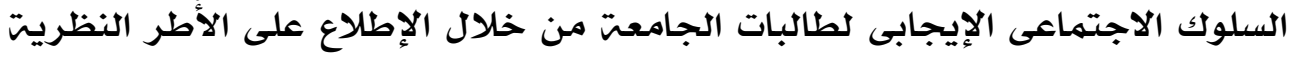

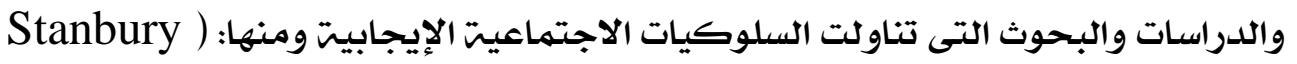

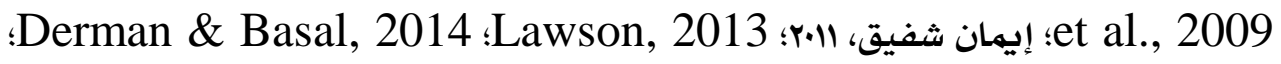
El-Mallah, 2014

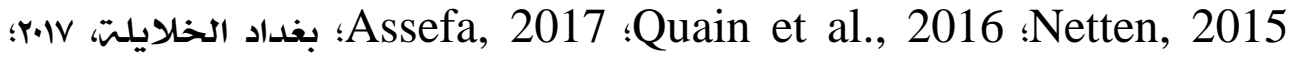

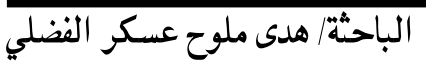




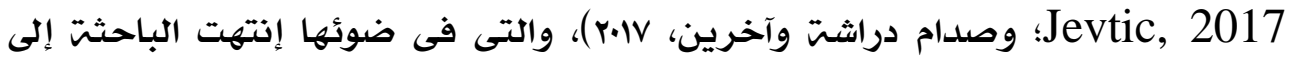

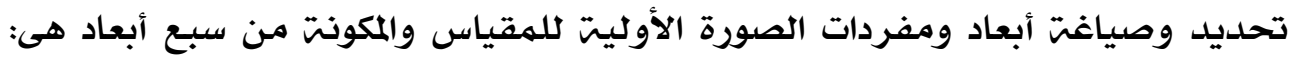

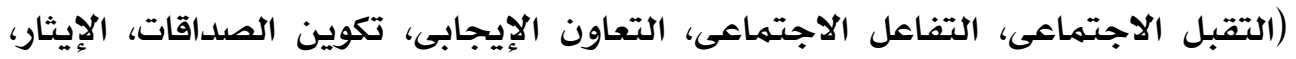

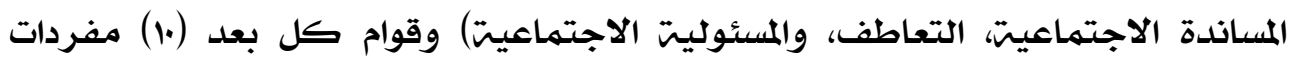
ليصبح المقياس فى صورته الأوليت (•م) مفردة.

الخصائص السيكومترية للمقياس:

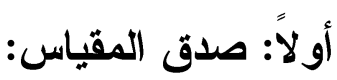

1- صدق المحكمّين: تم عرض المقياس على مجموعت من السادة المحكمين من

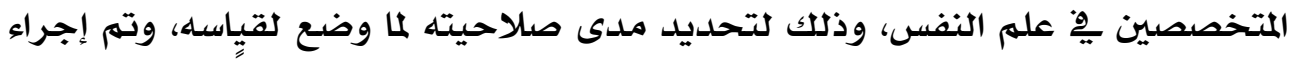

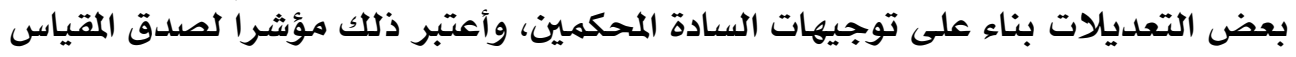

$$
\text { حيث تراوحت نسبت الاتفاق ما بين (•N - ..1\%). }
$$

Y- الصدق البنائى: تم التحقق من الصدق البنائي للمقياس من خلال إيجاد

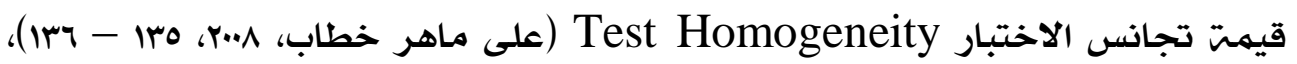

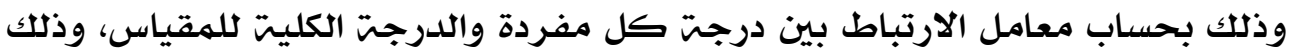

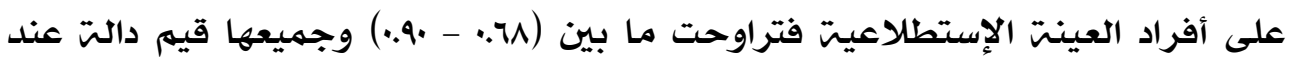

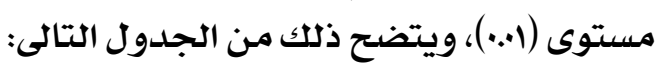

جدول (1) معاملات الارتباط بين درجت كل مفردة والدرجت الكليت للمقياس ككل

\begin{tabular}{|c|c|c|c|c|c|c|c|c|c|}
\hline الارتباط & المفردة & الارتباط & المفردة & الارتباط & المفردة & الارتباط & المفردة & الارتباط & المفردة \\
\hline .71 & 70 &.$V Y$ & $\varepsilon 9$ & $\cdot V A$ & rr & .79 & IV & $\cdot . \Lambda$. & 1 \\
\hline. .79 & 77 & $\cdot V \varepsilon$ & 0. &.$V O$ & $r \varepsilon$ &.$V \varepsilon$ & 11 &..$V 1$ & $r$ \\
\hline$\cdot . A V$ & TV & $\cdot . \wedge$. & 01 &.$\wedge \varepsilon$ & ro & $\cdot .10$ & 19 & .711 & $r$ \\
\hline$\because 9$. & 71 & .9 . & or & $\cdot V r$ & $r q$ & $\cdot V O$ & $r$. & $\cdot .19$ & $\varepsilon$ \\
\hline
\end{tabular}


السلوك الاجتماعى الإيجابى لدى طالبات الكليات العلية والإنسانية

\begin{tabular}{|c|c|c|c|c|c|c|c|c|c|}
\hline$\cdot V V$ & 79 &.$V V$ & or &.$V \varepsilon$ & PV & $\cdot . A V$ & $M$ &.$V T$ & 0 \\
\hline •. & v. &. .11 & $\Delta \varepsilon$ & r.AT. & rA & .71 & $r r$ & .71 & 7 \\
\hline$\cdot V \varepsilon$ & VI &.$V^{r}$ & $\Delta \Delta$ & .017 & $r q$ &. VO & $r r$ &. .71 & $v$ \\
\hline . VY & VY &.$V A$ & 07 &.$V \varepsilon$ & $\varepsilon$. & .077 & $r \varepsilon$ & $\cdot .11$ & $\wedge$ \\
\hline$\cdot . \Lambda$ • & Vr &. .19 & OV & ..$\wedge \varepsilon$ & $\sum 1$ & $\cdot .10$ & ro & .9. & 9 \\
\hline$\cdot . \wedge 1$ & $V \varepsilon$ &.$V T$ & $\Delta \Lambda$ &.$\vee V A$ & $\varepsilon r$ & .077 & $M$ &.$\vee V \varepsilon$ & 1. \\
\hline$\cdot V I$ & vo & .077 & 09 & $\cdot . v$. & $\varepsilon r$ & .71 & PV & $\cdot . V$. & 11 \\
\hline$\cdot V A$ & Vy & $\cdot . V$. & 7. &..$V T$ & $\varepsilon \varepsilon$ & $\cdot .9$. & $r \wedge$ &. VO & Ir \\
\hline. .19 & VV & .71 & 71 & $\cdot . \wedge A$ & $\varepsilon 0$ &.$V V$ & $r q$ &.$V A$ & Ir \\
\hline$\cdot . \Delta V$ & $V A$ & $\cdot . V A$ & $7 r$ & $\cdot . \wedge \cdot$ & $\varepsilon 7$ & $\cdot . \wedge \cdot$ & $r$. & $\cdot . \wedge \varepsilon$ & $1 \varepsilon$ \\
\hline$\cdot .1 \mathrm{~A}$ & va & .9. & $7 r$ & $\cdot . V$. & $\varepsilon V$ &. .79 & H & $\cdot . \Lambda$. & 10 \\
\hline$\cdot .19$ & A. & $\cdot A \Lambda$ & $7 \varepsilon$ & .077 & $\varepsilon \wedge$ &.$V A$ & rr &.$V^{r}$ & 17 \\
\hline
\end{tabular}

ثانياً: ثبات المقياس: قامت الباحثت بحساب ثبات المقياس بطريقت ألفا كرونباخ وذلك

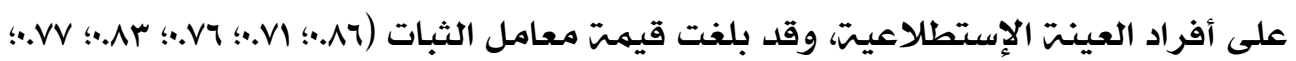

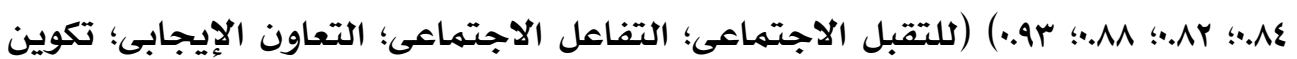

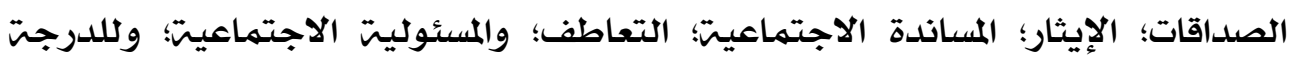

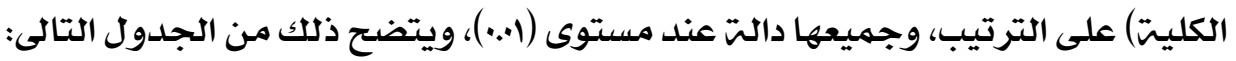

جدول (ץ) قيم معاملات ثبات مقياس السلوك الاجتماعى الإيجابى

\begin{tabular}{|c|c|}
\hline طريقت ألفا كرونباخ الثبات - ألفا & أبعاد المقياس \\
\hline & التقبل الاجتماعى \\
\hline$\cdot . \mathrm{VI}$ & التفاعل الاجتماعى \\
\hline $.0 \mathrm{VI}$ & التعاون الإيجابى \\
\hline$\cdot \wedge r$ & تكوين الصداقات \\
\hline$\because V V$ & الإيثار \\
\hline$\cdot \wedge \varepsilon$ & المسـاندة الاجتهـاعيت \\
\hline$\because \wedge r$ & التعاطف \\
\hline$\cdot . \wedge 1$ & لمسئوليت الاجتتماعيت \\
\hline
\end{tabular}

الباحثة/ هدى ملوح عسكر الفضلي 
من الإجراءات السـابقت تأكد للباحثت صدق وثبات مقياس السلوك الاجتهاعى

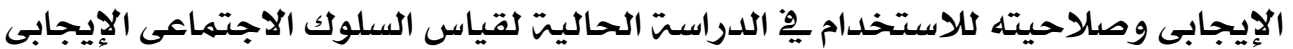

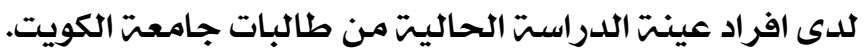

\section{نتائج الار اســـة وتفسيرها:} ا - نتائج الفرض الأول وتفسيرها:

ينص الفرض الأول على أنه "لا توجد فروق دالة إحصائياً بين درجة المتوسط الفرضي ومتوسط درجات عينة الدراسة (طالبات جامعة الكويت) على مقياس السلوك الاجتماعى الإيجابى". وللتحقق من وللتحقق من صحت هذا الفرض

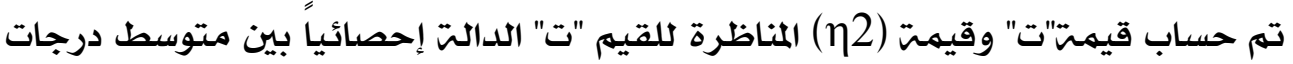

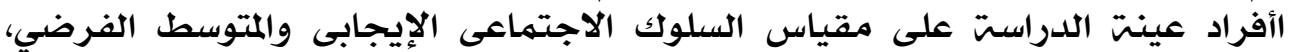

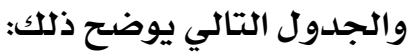

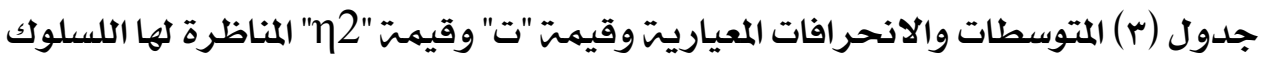
الاجتماعى الإيجابى والمتوسط الفرضي

\begin{tabular}{|c|c|c|c|c|}
\hline التأثبر & "تيمت" & $\varepsilon$ & r & الاجتماعى الإيجال السلوكى \\
\hline$r . \varepsilon r$ & YV.PY & r. & $8 . .7$ & التقبل الاجتماعى. \\
\hline$r .0 \mathrm{~V}$ & YM.IV & . & 8.99 & التفاعل الاجتماعى. \\
\hline 0.11 & \&.9. &.$\& \mathrm{~V}$ & \&.Y. & التعاون الإيجابى. \\
\hline r.97 & MI.Yo & .00 & 8.9 & تكوين الصداقات. \\
\hline$r .01$ & YA.YE & .09 & $\varepsilon .0$ & الإيثار. \\
\hline$\varepsilon .19$ & rr.Yr & $.0 \%$ & 8.11 & المساندة الاجتهاعيتة. \\
\hline
\end{tabular}

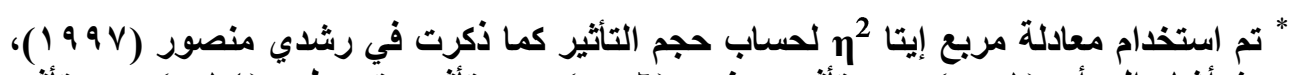

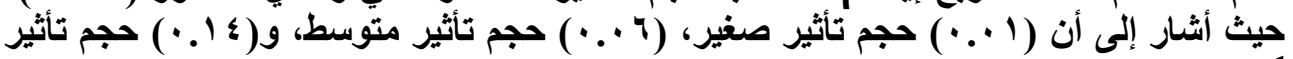


السلوك الاجتماعى الإيجابى لدى طالبات الكليات العلمية والإنسانية

\begin{tabular}{|c|c|c|c|c|}
\hline$\varepsilon . \mu$ & M.AY & $.0 \%$ & $\varepsilon .+7$ & التعاطف. \\
\hline$\varepsilon . \mu \wedge$ & r\&.00 & . .04 & \&.IV & المسئوليت الاجتماعيت \\
\hline $0 . Y$. & $\varepsilon .9 V$ & $\cdot . \$ 7$ & S.YI & الدرجت الكليت \\
\hline
\end{tabular}

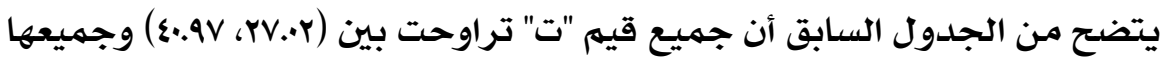

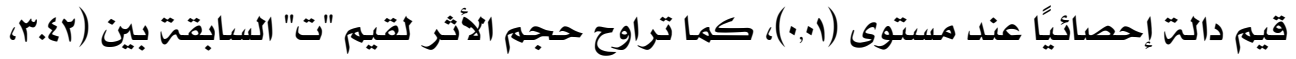

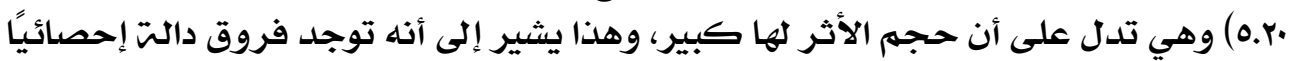

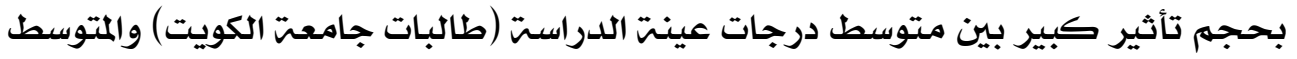

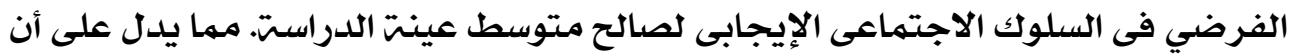

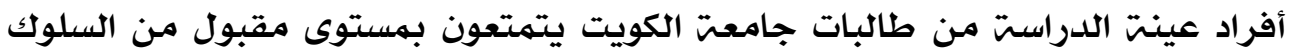

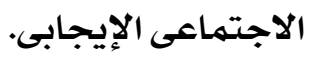

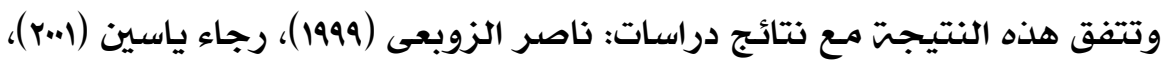

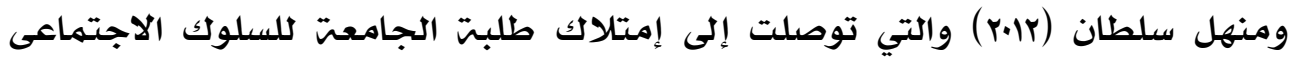
الإيجابى. ومئن

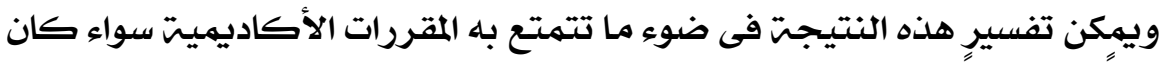

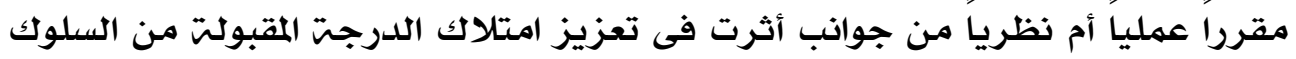

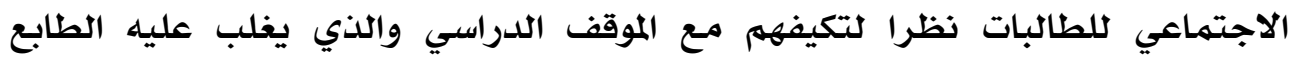

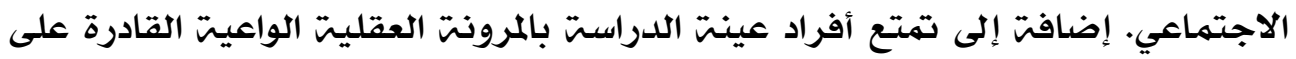

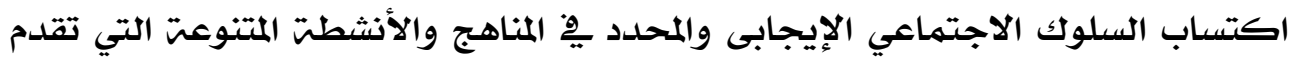

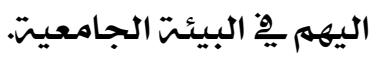

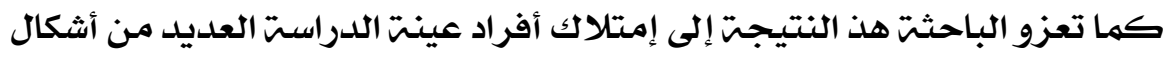

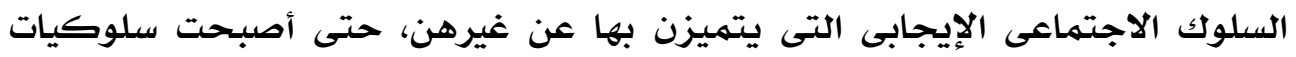

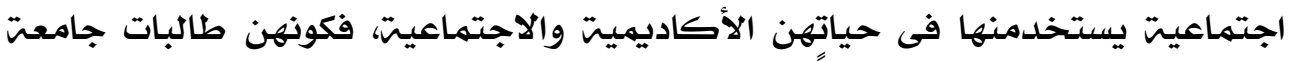

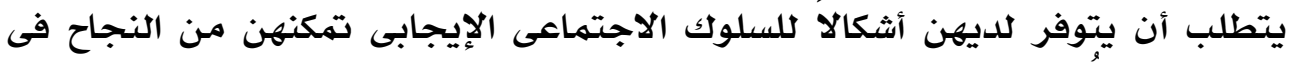

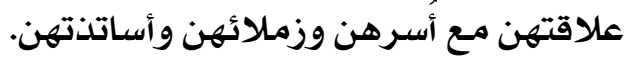
r- نتائج القرض الثاني وتفنيرها: ينص الفرض الثاني على أنه "لا توجد فروق دالة إحصائياً بين طالبات جامعة الكويت فى السلوك الاجتماعى الإيجابى تبعاً للتخصص الاراسى "توع الكلية" (علمية - إنسانية)". وللتحقق من صحت هذا الفرض فقد تم حساب المتوسط 
والانحراف المعياري وقيمتة "ت" للسلوك الاجتهاعى الإيجابى تبعا للتخصص الدراسى "نوع

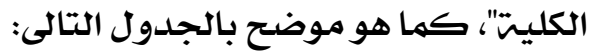

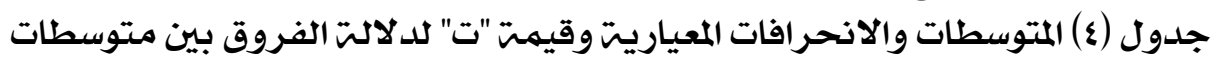

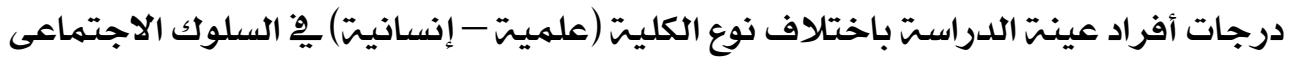
الإيجابى.

\begin{tabular}{|c|c|c|c|c|c|c|c|}
\hline مستوى الدلات & قيهـ "ت" & D.F & $\varepsilon$ & $\boldsymbol{r}$ & ن & الكليت & 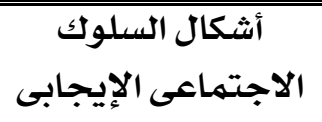 \\
\hline \multirow{2}{*}{ غير } & \multirow[t]{2}{*}{$1.81 Y-$} & \multirow[t]{2}{*}{191} & 1.19 & $1 V .01$ & 90 & علهيت & \multirow[t]{2}{*}{ التقبل الاجتهماعى. } \\
\hline & & & 1.91 & $1 V . \wedge 9$ & 1.0 & إنسانيت & \\
\hline 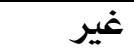 & \multirow{2}{*}{$. . £ 01-$} & \multirow[t]{2}{*}{191} & $r$ & $M .94$ & 90 & علهيت & \multirow[t]{2}{*}{ التفاعل الاجتماعى. } \\
\hline دالت & & & r & 19.97 & 1.0 & إنسانيتت & \\
\hline 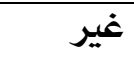 & \multirow{2}{*}{$.9 Y r-$} & \multirow[t]{2}{*}{191} & $\cdot \wedge 7$ & $19 .+4$ & 90 & علميتة & \multirow[t]{2}{*}{ التعاون الإيجابى. } \\
\hline دالت & & & 1.1. & 19.17 & 1.0 & إنسانيت & \\
\hline غير & \multirow[t]{2}{*}{$. .000-$} & \multirow[t]{2}{*}{191} & $1 . V \cdot$ & $10 . £ V$ & 90 & علهيت & \multirow[t]{2}{*}{ تكوين الصداقات. } \\
\hline دالت & & & $1.9 \mathrm{~V}$ & 10.71 & 1.0 & إنسانيت & \\
\hline غير & \multirow[t]{2}{*}{$\cdot . \Sigma \mu V-$} & \multirow[t]{2}{*}{191} & r & 19 & 90 & علهيت & \multirow[t]{2}{*}{ الإيثار. } \\
\hline دالت & & & 1.99 & $19.1 Y$ & 1.0 & إنسانيت & \\
\hline غير & \multirow[t]{2}{*}{$.7 Y 0-$} & \multirow[t]{2}{*}{191} & .97 & 19.0 & 90 & علهيت & \multirow[t]{2}{*}{ المسـاندة الاجتهماعيتت. } \\
\hline دالت & & & 1.97 & $19.1 \varepsilon$ & 1.0 & إنسانيتت & \\
\hline غير & \multirow[t]{2}{*}{$\because \wedge \vee-$} & \multirow[t]{2}{*}{191} & $1.9 \cdot$ & IV.VO & 90 & علهيتة & \multirow[t]{2}{*}{ التعاطف. } \\
\hline دالت & & & 1.10 & IV.VA & 1.0 & إنسانيتة & \\
\hline 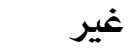 & \multirow[t]{2}{*}{$\because 7 \cdot 1-$} & \multirow[t]{2}{*}{191} & r & IV.9r & 90 & علهيت & \multirow[t]{2}{*}{ المسئوليت الاجتهماعيت } \\
\hline دالت & & & Y.1. & 11.11 & 1.0 & إنسانيتت & \\
\hline غير غ & \multirow[t]{2}{*}{$.9 \vee \wedge-$} & \multirow[t]{2}{*}{191} & A.7. & $|\varepsilon \varepsilon . V|$ & 90 & علهيت & \multirow[t]{2}{*}{ الدرجت الكليتي } \\
\hline دالت & & & A. V. & $1 \leqslant 0.9$. & 1.0 & إنسانيتن & \\
\hline
\end{tabular}

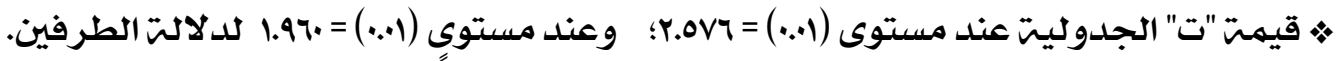

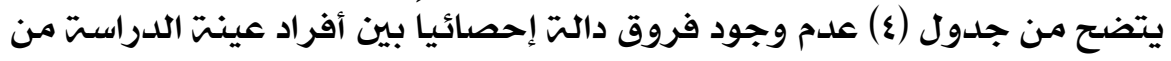

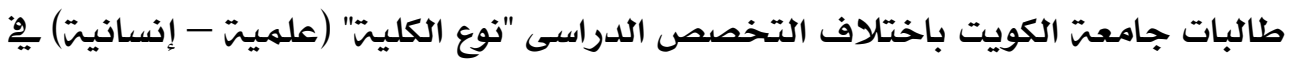

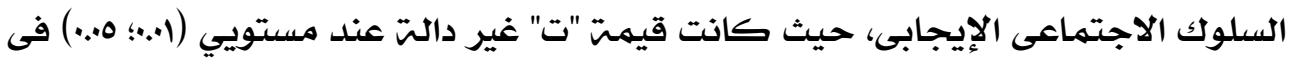

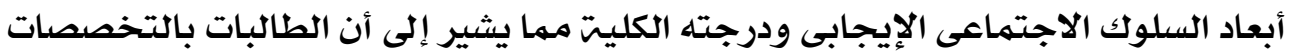

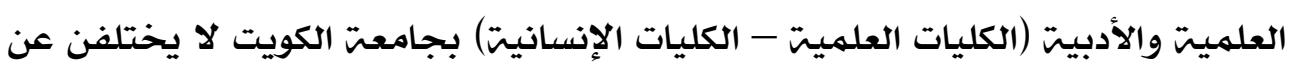


السلوك الاجتاعى الإيجابى لدى طالبات الكليات العلية والإنسانية

بعضهن البعض يْ أشكال السلوك الاجتماعى الإيجابى، وهو ما يشير إلى تحقق الفرض الثانى للدراست الحاليت.

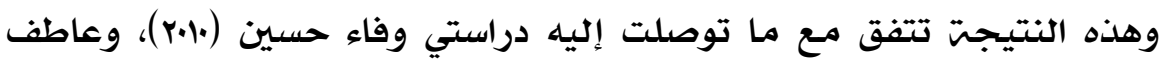

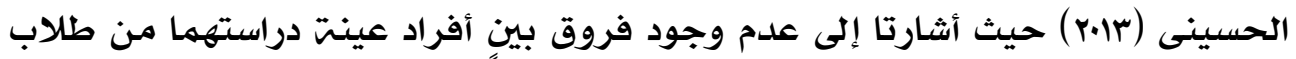

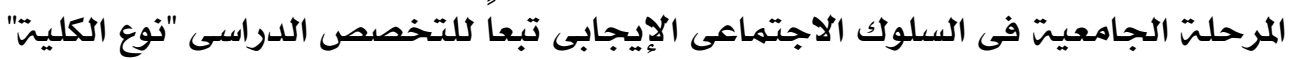

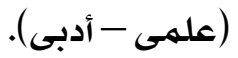

ويهكن تفسير ذلك التقارب الكبير فى السلوك الاجتهاعى لطالبات كل من فن

الكليات العلميتت والإنسانيت بجامعت الكويت، فى ضوي أن السلوك الاجتهماعى الإيجابى

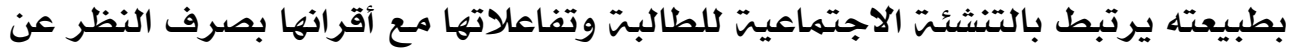
تخصصها الدراسى "نوع كليتها" سواء كانت علميتش أو إنسانيت. إضنافت إلى أن أفراد عينت

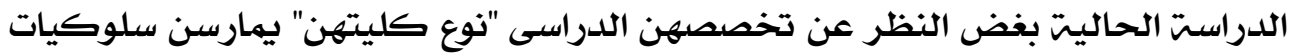

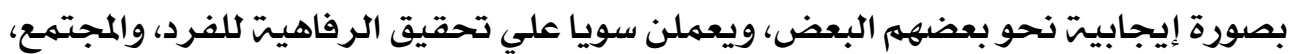

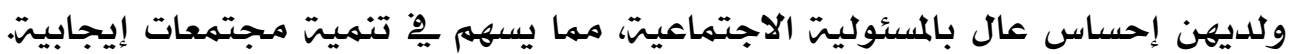
كما يمارسن السلوك الاجتماعي الإيجابي من خلاجل عمليت التفاعل الاجتماعياعي، وزيادة

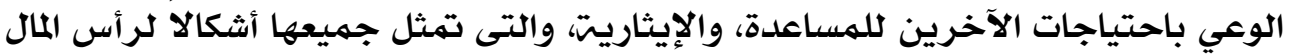

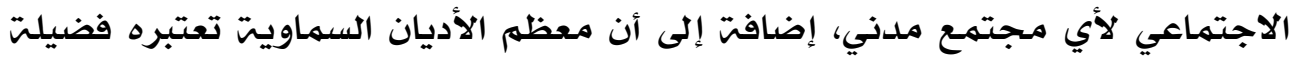
روحانيت.

وهناك العديد من أوجه الاستفادة من الدراست الحاليتّ يهكن تلخيصها فيما يلي:

ا- قدمت الدراست مقياسا للسلوك الاجتماعي الإيجابي والذى أعدته الباحثت

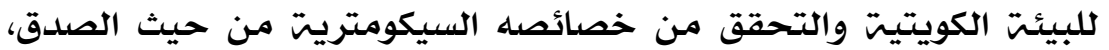

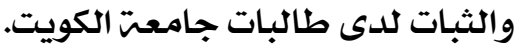

ץ- تم توضيح أشكال السلوك الاجتماعى الإيجابى الشائعت والمنتشرة لدى طالبات جامعت الكويت من أجل تقديه برامـ التدخل السيكولوجى المناسبت

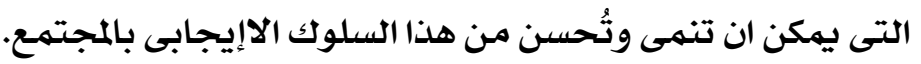
ץ- تمت مقارنت السلوك الاجتماعى الإيجابى بين طالبات الكليات العلميت بجامعت الكويت ونظير اتهن فى الكليات الإنسانيت. ع- فضلا عن ذلك فإنه فى حلدود إطلاع الباحثت تعد هذه الدراستّ هي الأولى من

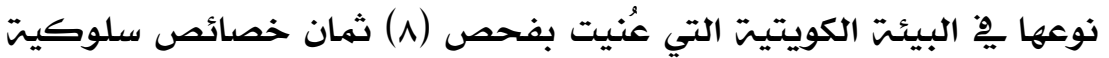
اجتماعيتت إيجابيت يِّ آن واحلد و لدى نوعين مـختلفين من الدراست (علميت -

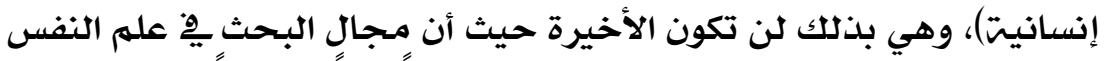

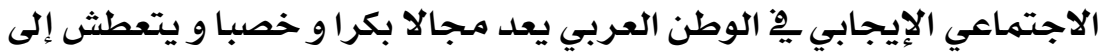

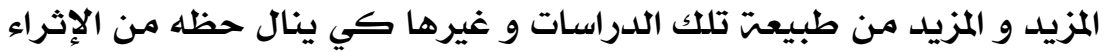
البحثي و المعلوماتي أسوة بالصعيد المريدي العالمي.

الباحثة/ هدى ملوح عسكر الفضلي 
بلة كلية الآداب جامعة الزقازيق

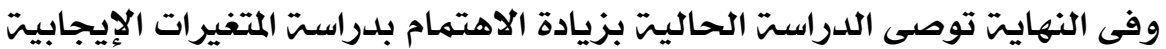

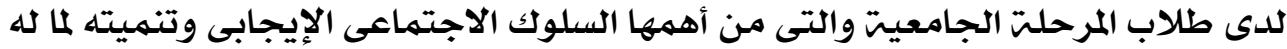

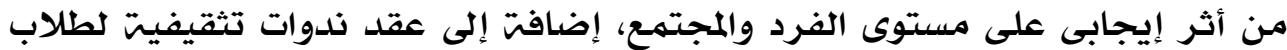

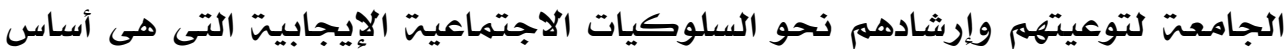

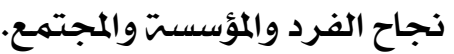




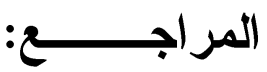

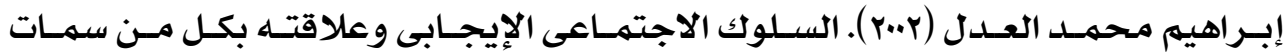

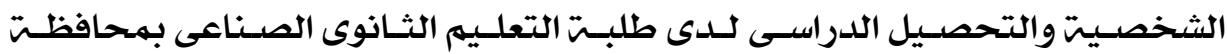

الشرقيت. رسالة ماجستير، كليت التربيت، جامعت الزقازيق. أحمد حاشـوش الخالدى (.l.r) ). بعض المتغيرات النفسيت والاجتماعيـت المرتبطت بالسـلوك الاجتهـاعى الإيجابى لدى طلاب وطالبـاتى المدارس الثانويـت بدولـت الكويـ. المؤثمر السنوى الخامس عشر لمركز الإرشـاد الأفسى بجامعة عين شمس (الإرشـاد الأسرى وتتمية المجثمع - نحو آفاق إرشادية رحبــة)، خـلال الفترة مـن - ع

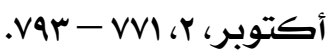

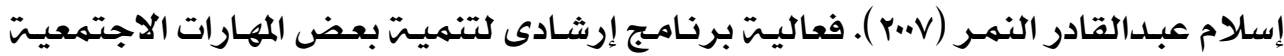
لدى التلاميذ بطيئي التعله.رسالة ماجستير، كليت التربيتة جامعت بنها.

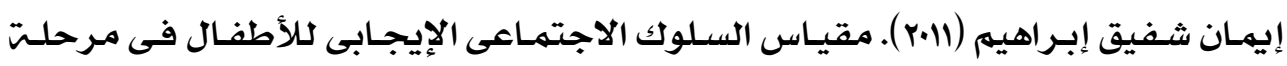
الروضـت كهـاتقـدره الأمهات. المؤتمر السنوى السادس عشر لمركز الإرشــاد النفسى بجامعة عين شمس (الإرشاد النفسى وإرادة التغييز - مصر بعد ثورة

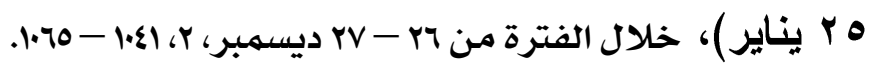

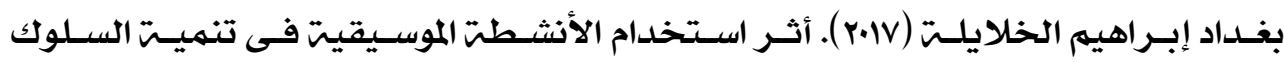
الاجتهـاعى الإيجــابى لـدى طلبـت الصـف السـادس الأسـاسـى فـى الأردن. رســـــالة ماجستيزر، كليت الدراسات العليا، الجامعت الهاشهيتة، الأردن.

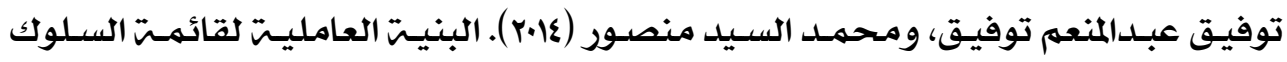
الاجتماعي الإيجابي: دراست عبر ثقافيتة. المجلة المصرية للارزاسات النفسية، ع

$$
. \Sigma V-1, r_{6}(\Lambda \mu)
$$

جابر عبدالحميد جابر، وعلاء الدين محمد كفافى (1991). معجم علم النفس والطــب

$$
\text { (ج ^). القاهرة: دار لنهضت العربيت. }
$$




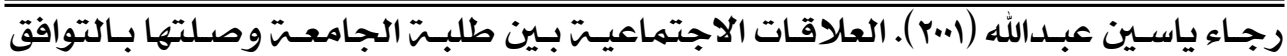
النفسى والتحصيل الدراسى. رسالة دكتور اه، كليت التربيت ابن رثلد، جامعت بغداد، العراق.

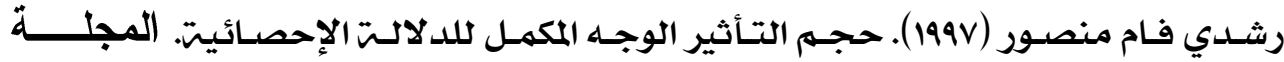

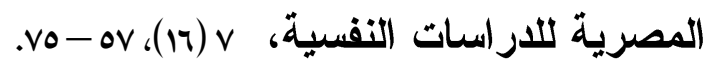

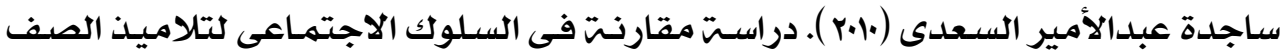
الاول الابتدائى الملتحقين وغير الملتحقين برياض الأطفال. در اسات تربويـــة، . 1.

$$
.11 r-79
$$

سـيد أحمد عثمـان (.ا.r). التحليل الأخلافي للمســئولية الاجتماعيــة (ط r). القـاهرة: مكتبت الأنجلو المصريت. صالح حسين (rا.r). وسائل قياس الشخصية. القاهرة: دار الكتاب الحديث.

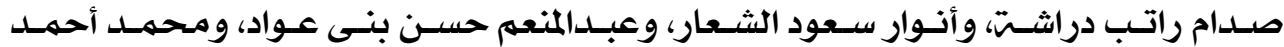

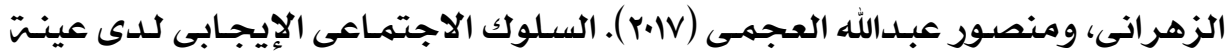

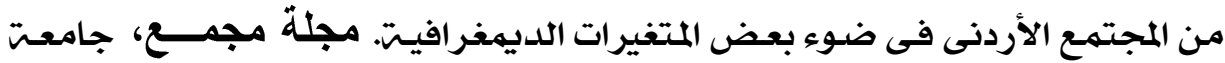

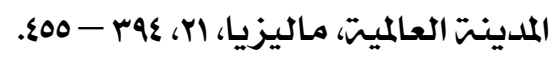

صلاح مخيهر (1911). في إيجابية التو افثى. القاهرة: مكتبت الأنجلو المصريت. عاطف مسعد الحسينى (rا.r). القيهت التتبؤيت لعوامل الشخصيت الخمست الكبرى والعفو

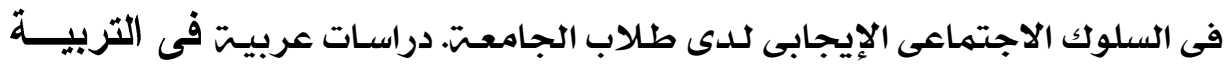

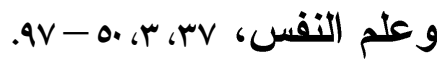

عبـاس نوح الموسـوى (Y..r). السـلوك الاجتهـاعى وعلاقتـه بالشعور بالـذات والامـن النفسىى لدى طلبت جامعت الموصل. رسالة ماجستير، كليت التربيت، جامعت الموصل، العراق. عبد الحافظ سلامت (V..v). علم النفس الاجتماعي. عمان: دار اليـازوري العلميـت للنشـر والتوزيع. عبدالفتاح رجب مطر (Y..r). فاعليت السيكودراما فى تنميت بعض المهارات الاجتماعيت لدى الصهم. رسالة دكتور اه، كليت التربيت ببنى سويف، جامعت القاهرة. 


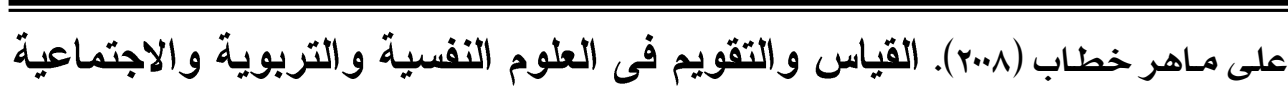

$$
\text { (ط V) القاهرة: مكتبت الانجلو المصريت. }
$$

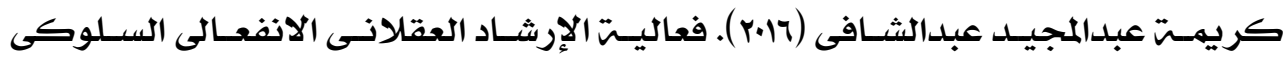

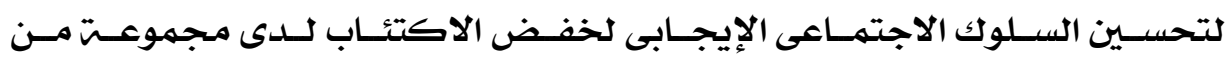

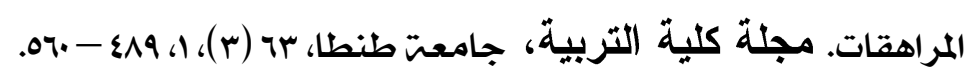

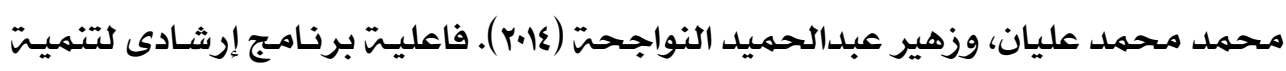

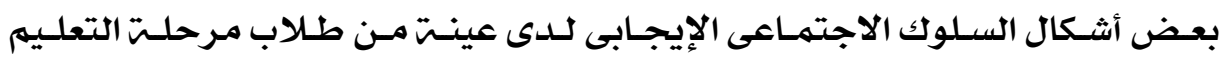

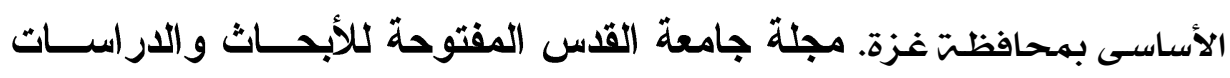

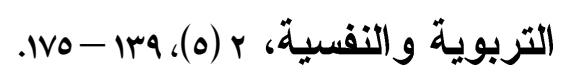

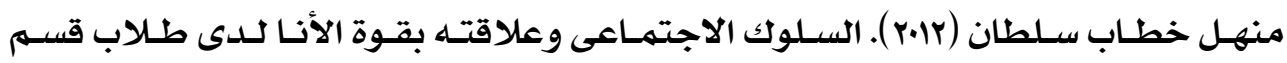
التربيت الرياضيت في كليت التربيت الأساسيت جامعت الموصل. مجلة أبحاث كليــة

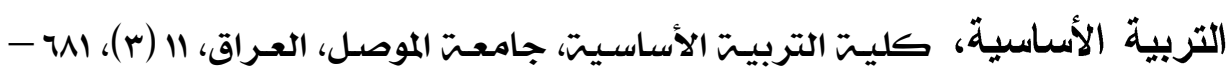

.$V 1$.

منى بدر الجناعى (10.r). برنامج إرشادى لتنميت السلوك الاجتماعى الإيجابى لدى أطفال

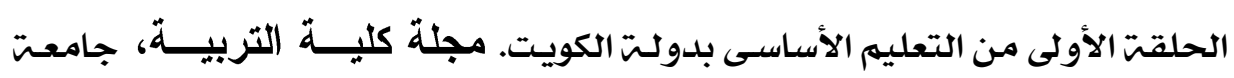

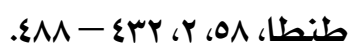

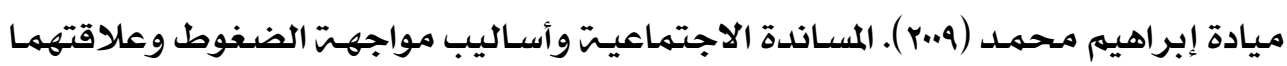

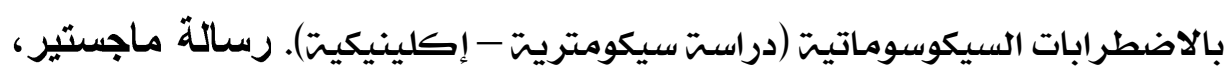
كليت التربيتة جامعت الزقازيق. ناصر هراط الزوبعى (1999). الصحت النفسيتة وعلاقتها بالتفاعل الاجتماعى لدى طلبتة

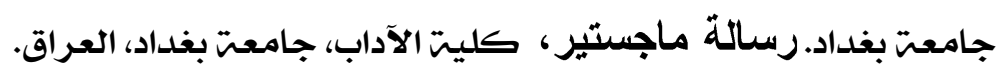

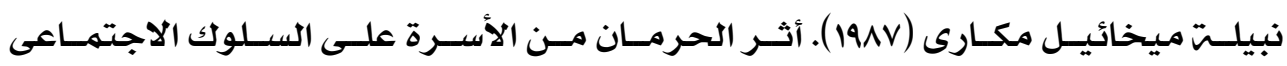

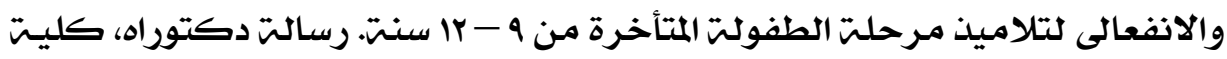

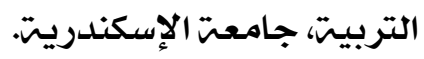

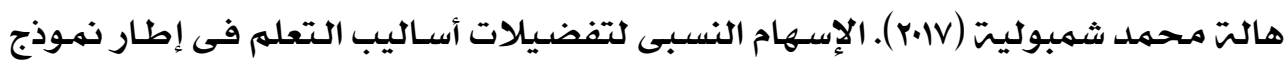

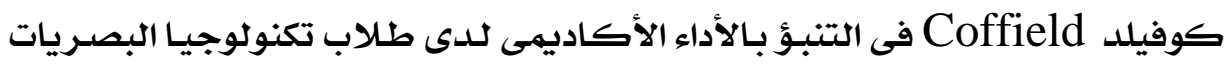


مرتفعى ومنخفضى السلوك الإيثارى. مجلة كلية التربيـلة، جامعتة بنها، بY (III)،

$$
\text { . YQ\& - r०9 }
$$

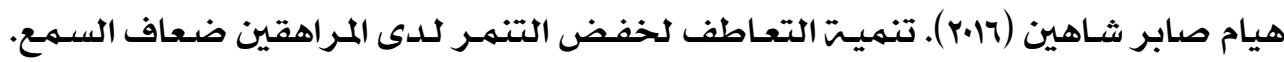
المجلة المصرية للار اسات النفسية، جr (9)، I،

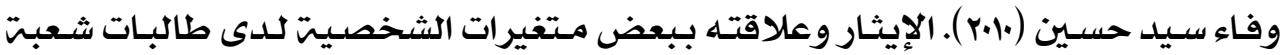

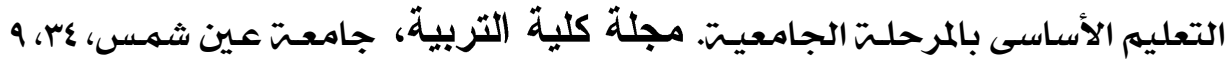

$.1 \cdot 0-$

Assefa , E .(2017). Good social skills are pivotal in academic Success Retrieved from http:/coolschoolcentral.com/2017/07/07/_ good-socialskillspivotal-academic-succes.

Bower, A. A. (2012). What We Do When Children Are Good:

How Parents. Reinfoce their Preschool Children's Prosocial Behaviors and the Effectiveness of these Strategies across Contexts. Unpublished Doctoral Dissertation, University Of Nebraska.

Carlo, Gustavo; Koller, Silvia H.; Eisenberg, Nancy; Da Silva, Marcia S.; Frohlich, Claudia B.(1996). A cross-national study on the relations among prosocial moral reasoning, gender role orientations, and prosocial behaviors. Developmental Psychology, 32 (2), 231-240.

Clary, G. (1994). Altruism and Helping Behavior, Encyclopedia of Human behavior, 1, 93- 102.

Derman, M. T. \& Basal, H. A. (2014). The impact of empathy education program which was performed on 10-11 year old children from different socioeconomic levels on the aggression level. Procedia - Social and Behavioral Sciences, $141,1049-1053$. 
El-Mallah, S. (2014). Social behavior and academic performance: Examining relations between forms of prosocial behavior and aggression in predicting academic outcomes, Master of Science in Psychology, faculty of the Virginia Polytechnic Institute.

Jevtic, B. S. (2017).The attitude of teachers towards prosocial behavior and academic achievement in Serbia, Problems of Education in the 21st Century, 75 (1), 34-53.

Kennedy, K. M. (2011). Subject Disposition and Individuals

Differences Association with Prosocial donor Behaviors. Unpublished Doctoral Dissertation, University of Fordham.

Kumru, Asiye; Carlo, Gustavo;Mestre, Maria V; Sample, Paula. (2012). Prosocial moral reasoning and prosocial behavior among Turkish and Spanish adolescents. Social Behavior and Personality, 40 (2), 205-214.

Lawson. A. (2013). Teaching empathy through literature lessons to alleviate bullying. Unpublished doctoral dissertation, The faculty of Wilmington University.

Netten, A. P. (2015). Low empathy in deaf and hard of hearing (Pre) adolescents compared to normal hearing controls. PLOSONE, DOI: 10.1371/journal.pone.0124102 Olweus, D. (1993). Bullying at school. Oxford, Uk: Blackwell Publishing Company.

Quain ,S.; Yidana, X.; \& Ambotumah, B .(2016). Pro-social Behavior amongst Students of Tertiary Institutions: An Explorative and a Quantitative approach, Journal of Education and Practice, 7 (9), 26-33.

Sahin, M. (2012). An investigation into the efficiency of empathy training program on preventing bullying in primary 
schools. Children and Youth Services Review, 34 (7), 13251330.

Stanbury; Wyoming; Bruce; Jain; \& Stellern. (2009). The effects of an empathy building program on bullying behavior. Journal of School Counseling, 7 (2), 1- 27.

Yildiz, M. A. \& Duy, B. (2013). Improving empathy and communication skills of visually impaired early adolescents through a psycho education program. Educational Sciences: Theory \& Practice, 13 (3), 1470-1476.

Zhang, Y. \& Tsui, A. (2009). Intergroup Functional Diversity and Intergroup Relations in American and Chinese Workgroups. Journal of Cross-Cultural Psychology, 1 (40), 845-850.

\section{Positive social behavior among students of scientific and humanities Colleges University of Kuwait (Comparative Study)}

\section{Prepared by}

Hoda Mallouh Askar ALFadhli

Assistant Teacher Psychology - Department of Psychology

Faculty of Social Sciences - Kuwait University

\section{$\underline{\text { Summary }}$}


The objective of the current study was to identify the positive social behaviors prevalent among Kuwait University students and to identify the differences in positive social behavior among the students of the scientific faculties of Kuwait University and their counterparts in the human faculties. (95) students in scientific colleges and (105) female students in humanitarian colleges, ranging in age from $(18-20)$ years with an average of (19.51) years. and a standard deviation of (1.78) years. The results of the study indicated the following: There are statistically significant differences in the size of significant effect between the average score of the sample of the study (Kuwait University students) and the average satisfactory in positive social behavior in favor of the average sample of the study. There are no statistically significant differences between the students of Kuwait University in positive social behavior according to the specialization of the study "type of college" (scientific humanitarian).

Keywords: Positive Social Behavior - Scientific Colleges Human Faculties. 